\title{
Exacerbation of Epilepsy by Astrocyte Alkalization and Gap Junction Uncoupling
}

\author{
Mariko Onodera, ${ }^{1}{ }^{\circledR}$ Jan Meyer, ${ }^{2}$ Kota Furukawa, ${ }^{1}$ Yuichi Hiraoka, ${ }^{3}$ Tomomi Aida, ${ }^{3}{ }^{\oplus}$ Kohichi Tanaka, ${ }^{3}$ \\ ${ }^{\circledR}$ Kenji F. Tanaka, ${ }^{4}$ Christine R. Rose, ${ }^{2}$ and ${ }^{\circledR}$ Ko Matsui ${ }^{1}$ \\ ${ }^{1}$ Super-network Brain Physiology, Graduate School of Life Sciences, Tohoku University, Sendai 980-8577, Japan, ${ }^{2}$ Institute of Neurobiology, Faculty \\ of Mathematics and Natural Sciences, Heinrich Heine University Düsseldorf, 40225 Düsseldorf, Germany, ${ }^{3}$ Laboratory of Molecular Neuroscience, \\ Medical Research Institute (MRI), Tokyo Medical and Dental University (TMDU), Tokyo 113-8510, Japan, and ${ }^{4}$ Laboratory of Department of \\ Neuropsychiatry, School of Medicine, Keio University, Tokyo 160-8582, Japan
}

Seizures invite seizures. At the initial stage of epilepsy, seizures intensify with each episode; however, the mechanisms underlying this exacerbation remain to be solved. Astrocytes have a strong control over neuronal excitability and the mode of information processing. This control is accomplished by adjusting the levels of various ions in the extracellular space. The network of astrocytes connected via gap junctions allows a wider or more confined distribution of these ions depending on the open probability of the gap junctions. $\mathrm{K}^{+}$clearance relies on the $\mathrm{K}^{+}$uptake by astrocytes and the subsequent diffusion of $\mathrm{K}^{+}$through the astrocyte network. When astrocytes become uncoupled, $\mathrm{K}^{+}$clearance becomes hindered. Accumulation of extracellular $\mathrm{K}^{+}$leads to hyperexcitability of neurons. Here, using acute hippocampal slices from mice, we uncovered that brief periods of epileptiform activity result in gap junction uncoupling. In slices that experienced short-term epileptiform activity, extracellular $\mathrm{K}^{+}$transients in response to glutamate became prolonged. $\mathrm{Na}^{+}$imaging with a fluorescent indicator indicated that intercellular diffusion of small cations in the astrocytic syncytium via gap junctions became rapidly restricted after epileptiform activity. Using a transgenic mouse with astrocyte-specific expression of a $\mathrm{pH}$ sensor (Lck- $\mathrm{E}^{2} \mathrm{GFP}$ ), we confirmed that astrocytes react to epileptiform activity with intracellular alkalization. Application of $\mathrm{Na}^{+} / \mathrm{HCO}_{3}{ }^{-}$cotransporter blocker led to the suppression of intracellular alkalization of astrocytes and to the prevention of astrocyte uncoupling and hyperactivity intensification both in vitro and in vivo. Therefore, the inhibition of astrocyte alkalization could become a promising therapeutic strategy for countering epilepsy development.

Key words: astrocyte; epilepsy; gap junction; $\mathrm{Na}^{+} / \mathrm{HCO}_{3}{ }^{-}$cotransporter; $\mathrm{pH}$; potassium

Significance Statement

We aimed to understand the mechanisms underlying the plastic change of forebrain circuits associated with the intensification of epilepsy. Here, we demonstrate that first-time exposure to only brief periods of epileptiform activity results in acute disturbance of the intercellular astrocyte network formed by gap junctions in hippocampal tissue slices from mice. Moreover, rapid clearance of $\mathrm{K}^{+}$from the extracellular space was impaired. Epileptiform activity activated inward $\mathrm{Na}^{+} / \mathrm{HCO}_{3}{ }^{-}$cotransport in astrocytes by cell depolarization, resulting in their alkalization. Our data suggest that alkaline $\mathrm{pH}$ shifts in astrocytes lead to gap junction uncoupling, hampering $\mathrm{K}^{+}$clearance, and thereby to exacerbation of epilepsy. Pharmacological intervention could become a promising new strategy to dampen neuronal hyperexcitability and epileptogenesis.

Received Sep. 10, 2020; revised Nov. 2, 2020; accepted Nov. 25, 2020.

Author contributions: M.O. and K.M. designed research; M.O. performed research; Y.H., T.A., K.T., and K.F.T. contributed unpublished reagents/analytic tools; M.O., J.M., and K.F. analyzed data; M.O., C.R.R., and K.M. wrote the paper.

This work was supported by Grant-in-Aid for Scientific Research on Innovative Areas "Glial assembly," "Non-linear Neuro-0scillology," and "Brain Information Dynamics" to K.M. (Grants 16H01325, 18H04932, 20H05046); Grant-in-Aid for Transformative Research Areas (A) "Glial Decoding" to K.M. (20H05896); Grant-in-Aid for Scientific Research (B) to K. M. (Grant 19H03338); Grant-in-Aid for Challenging Exploratory Research to K.M. (Grant 18K19368); Toray Science Foundation, The Salt Science Research Foundation, and Takeda Science Foundation to K.M.; Grant-in-Aid for JSPS Fellows to M.0. (Grant 19J12139). C.R.R received funding from the Priority Program SPP1757 of the German Research
Foundation (Grant Ro2327/8-2). J.M. and M.0. received funds from the YoungGlia network of the Priority Program SPP1757.

T. Aida's present address: McGovern Institute for Brain Research at MIT, Massachusetts Institute of Technology, 43 Vassar Street, Cambridge, MA 02139.

The authors declare no competing financial interests.

Correspondence should be addressed to Ko Matsui at matsui@med.tohoku.ac.jp.

https://doi.org/10.1523/JNEUROSCI.2365-20.2020

Copyright $\odot 2021$ the authors 


\section{Introduction}

The brain has a nearly infinite ability to change. The plasticity of neurons and synaptic transmission, which is associated with learning and memory, has been studied widely. However, the plasticity of glial functions has not been thoroughly addressed. Astrocytes, a major class of macroglial cells, form extensive networks of their own, which closely interact with neuronal circuits. The astrocyte circuit regulates the neuronal excitability and affects the mode of information processing in the brain (Pannasch et al., 2012).

Epilepsy (epi) is a common neuronal disorder characterized by hyperexcitability and seizures. Approximately $1 \%$ of people worldwide suffer from epilepsy, one-third of which show drug resistance (Kalilani et al., 2018). As most current antiepileptic drugs (AEDs) directly target neurons to suppress excess firing of action potentials, side effects are commonly observed with the administration of AEDs, which decreases the patients' quality of life (Chen et al., 2017). A promising alternative target is astrocytes. By controlling the ability of astrocytes to regulate neuronal excitability, a strategy to suppress epileptogenesis, rather than suppressing individual seizures, may be sought.

Astrocytes are connected intercellularly via gap junctions. It has been suggested that this gap junction coupling enables direct exchange of various substances, such as ions, transmitters, and metabolites (Verkhratsky and Kettenmann, 1996; Hirase et al., 2004; Verkhratsky and Kirchhoff, 2007; Escartin and Rouach, 2013; Verkhratsky and Nedergaard, 2018). Astrocytes can control the local brain environment and respond to vivid neuronal activity by adjusting the level of gap junction connections (Rouach et al., 2008). The local brain environment strongly influences seizure generation and/or cessation (Bélanger and Magistretti, 2009; Giaume et al., 2010; Jin and Chen, 2011; Pannasch et al., 2012; Pernelle et al., 2018; Li et al., 2019). For example, $\mathrm{K}^{+}$clearance from extracellular space is one of the key functions required for the cessation of hyperactivity (Bellot-Saez et al., 2017). Action potential firing of neurons leads to $\mathrm{K}^{+}$outflow, and the accumulation of extracellular $\mathrm{K}^{+}$leads to heightened neuronal excitability. $\mathrm{K}^{+}$are normally taken up by astrocytes and diffuse intercellularly through the astrocyte network via gap junctions. However, when gap junctions become uncoupled, this $\mathrm{K}^{+}$clearance process could become disrupted, an effect that seems to be especially critical under pathologic conditions (Steinhäuser et al., 2012; Bazzigaluppi et al., 2017; Du et al., 2018; Breithausen et al., 2020). With hampered $\mathrm{K}^{+}$clearance from the extracellular space, neurons would remain hyperexcitable for a prolonged time, which may further exacerbate seizures (de Curtis et al., 2018).

Such astrocyte uncoupling has been suggested to occur in the advanced stages of epilepsy. Astrocyte-specific deletion of connexins, on the other hand side, results in significantly higher seizure activity in mice (Deshpande et al., 2020). Previous studies have also suggested that gap junction uncoupling occurs by intracellular changes in $\mathrm{pH}$, which likely leads to phosphorylation of the connexin proteins (González-Nieto et al., 2008; Boedtkjer et al., 2013). Alkalization of astrocytes has been reported to occur during seizure-like activities in vitro (Raimondo et al., 2016). To reveal the chain of events leading to the exacerbation of seizures, we opted to use various tools to measure extracellular and intercellular ion dynamics in acute mouse hippocampal slices. We show that epileptiform activity leads to $\mathrm{Na}^{+} / \mathrm{HCO}_{3}{ }^{-}$cotransporter (NBC) activation, to intracellular alkalization in astrocytes, and to a partial gap junction uncoupling. By the pharmacological blockade of NBC, intracellular alkalization, gap junction uncoupling, and exacerbation of hyperactivity were prevented. The antiepileptic effect of the NBC blocker was also demonstrated in vivo. Our data thus demonstrate a functional plasticity of astrocytes in response to short-term hyperactivity of neurons, which apparently leads to exacerbation of epilepsy. By uncovering the mechanisms underlying the plasticity of astrocyte gap junctions, we were able to propose a possible target for suppressing epileptogenesis at a very early stage. This finding shows the powerful effects of the astrocyte state on the function of neuronal circuits. Such astrocyte plasticity may occur in both physiological and pathophysiological situations and contribute to the outstanding dynamism of the brain function.

\section{Materials and Methods}

This study was conducted in accordance with the recommendations of the Regulations for Animal Experiments and Related Activities at Tohoku University, and all experimental procedures were approved by the Institutional Animal Care and Use Committee of Tohoku University. Experiments on acute tissue slices performed at the Heinrich Heine University Düsseldorf were conducted in strict accordance with the institutional guidelines as well as the European Community Council Directive (2010/63/EU). All experiments were approved by the Animal Welfare Office at the Animal Care and Use Facility of the Heinrich Heine University Düsseldorf (institutional act no. O50/05). In accordance with the recommendations of the European Commission (Close et al., 1997); mice were anaesthetized with $\mathrm{CO}_{2}$ before the animals were quickly decapitated. All efforts were made to minimize animal suffering and to reduce the number of animals used.

Acute hippocampal slice preparation. Acute parasagittal hippocampal slices from mice [C57BL/6] or BALB/c mice; age, postnatal day 16 (P16) to P30; thickness, $250 \mu \mathrm{m}$ ] were prepared as described previously (Langer et al., 2012). Mice were deeply anesthetized, and the brain was removed and sliced in ice-cold artificial CSF (preparation ACSF) solution containing the following (in $\mathrm{mM}$ ): $125 \mathrm{NaCl}, 2.5 \mathrm{KCl}, 0.5 \mathrm{CaCl}_{2}, 6$ $\mathrm{MgCl}_{2}, 1.25 \mathrm{NaH}_{2} \mathrm{PO}_{4}, 26 \mathrm{NaHCO}_{3}$, and 20 glucose, bubbled with $95 \%$ $\mathrm{O}_{2}$ and $5 \% \mathrm{CO}_{2}, \mathrm{pH} 7.4,312-320 \mathrm{mOsm}$. Then slices were incubated in solution (normal ACSF) with $\mathrm{CaCl}_{2}$ and $\mathrm{MgCl}_{2}$ concentrations substituted to 2.0 and 1.0, respectively. For selective staining of the astrocytes in some experiments, slices were incubated in ACSF additionally containing $0.5-1 \mu \mathrm{M}$ sulforhodamine 101 (SR101; catalog \#S0025, Chemodex) at $32-34^{\circ} \mathrm{C}$ for $20 \mathrm{~min}$, and then incubated in ACSF without SR101 for a further $10 \mathrm{~min}$ (Nimmerjahn et al., 2004; Kafitz et al., 2008; Langer et al., 2012). After the incubation, slices were stored in ACSF at room temperature and used for recordings at room temperature $\left(22-25^{\circ} \mathrm{C}\right)$.

It has been reported that SR101 could also stain cells other than astrocytes, including oligodendrocytes (Hagos and Hülsmann, 2016; Hülsmann et al., 2017). However, using our staining protocol, it has been shown that SR101-positive cells in the hippocampus had both electrophysiological and morphologic properties of astrocytes (Kafitz et al., 2008; Schnell et al., 2012). Another study suggested that only $\sim 1 \%$ of the oligodendrocytes identified by specific GFP expression were stained by SR101 in hippocampus (Griemsmann et al., 2015). Therefore, we suggest that most of the SR101-labeled cells in our study were astrocytes.

To induce short-term epileptiform activity, slices were perfused with nominally $\mathrm{Mg}^{2+}$-free normal ACSF supplemented with a $\mathrm{GABA}_{\mathrm{A}}$ receptor antagonist [100 $\mu \mathrm{M}$ picrotoxin (Pic); catalog \#28004-71, Nacalai Tesque; $0 \mathrm{Mg}^{2+}$-Pic) for $15 \mathrm{~min}$. For some experiments, S0859 (50 $\mu \mathrm{M}$; catalog \#A15228, AdooQ Bioscience), a blocker of NBC, was supplemented in the $0 \mathrm{Mg}^{2+}$-Pic solution. To induce intracellular alkalization, slices were exposed to ACSF containing $20 \mathrm{mM} \mathrm{NH}_{4} \mathrm{Cl}$ for at most $8 \mathrm{~min}$. This solution was prepared by equimolar substitution for $\mathrm{NaCl}$. Chemicals were purchased from Nacalai Tesque or Sigma-Aldrich, unless otherwise noted.

Electrophysiological recordings. Whole-cell patch-clamp recordings were performed as described previously (Sasaki et al., 2012; Beppu et al., 2014). A hippocampal slice was transferred to a submerged-type 
recording chamber for the recording and continuously superfused. Pyramidal neurons in CA1 were visualized using a $60 \times$ water-immersion objective on an upright microscope equipped with infrared-differential interference contrast. Current-clamp recordings were performed with patch electrodes with resistances of 4-8 $\mathrm{M} \Omega$. A pipette solution with the following composition was used (in $\mathrm{mM}$ ): $112 \mathrm{~K}$-gluconate, 32 $\mathrm{KCl}, 10 \mathrm{HEPES}, 0.5$ EGTA, $4 \mathrm{MgCl}_{2}, 4 \mathrm{Na}_{2} \mathrm{ATP}$, and $0.5 \mathrm{NaGTP}$, pH 7.4, $\mathrm{KOH}$ for titration.

Fabrication and calibration of double-barreled $\mathrm{K}^{+}$-selective microelectrodes. The microelectrodes were prepared as described previously (Haack et al., 2015). Briefly, two borosilicate glass capillaries were fixed together, twisted with heat and pulled to a tip of $1 \mu \mathrm{m}$. The ion-sensitive barrel was silanized with hexamethyldisilazane, while the reference barrel was filled with distilled water to prevent its silanization. After silanization, capillaries were heated at $200^{\circ} \mathrm{C}$ for $2 \mathrm{~h}$ and kept dry until use. The tip of the ion-sensitive barrel was filled with 1-2 $\mu$ l of the ion-selective sensor (potassium ionophore I, Cocktail B, catalog \#99373, SigmaAldrich) and then backfilled with $100 \mathrm{~mm} \mathrm{KCl}$. The reference barrel was filled with HEPES-buffered saline as follows (in $\mathrm{mM}$ ): $125 \mathrm{NaCl}, 2.5 \mathrm{KCl}$, $2 \mathrm{CaCl}_{2}, 2 \mathrm{MgSO}_{4}, 1.25 \mathrm{NaH}_{2} \mathrm{PO}_{4}$, and 25 HEPES, pH 7.4, NaOH for titration. Then chlorinated silver wires were inserted into both barrels and sealed with dental wax. Electrodes were connected to a custom-made differential amplifier (input resistance, $R_{\mathrm{in}}=10 \mathrm{~T} \Omega$ ). The resistances of the $\mathrm{K}^{+}$-sensitive barrel and the reference barrel were 10-20 G $\Omega$ and 30-100 $\mathrm{M} \Omega$, respectively. The electrodes were calibrated by perfusion with salines containing different concentrations of $\mathrm{KCl}$, as described previously (Karus et al., 2015).

$\mathrm{K}^{+}$concentration recordings. Double-barreled $\mathrm{K}^{+}$ion-selective microelectrodes were used to compare extracellular $\mathrm{K}^{+}$concentration $\left(\left[\mathrm{K}^{+}\right]_{\mathrm{o}}\right)$ transients induced in control and epilepsy model slices. The microelectrodes were inserted into the stratum radiatum (s.r.) of the slices, and $\left[\mathrm{K}^{+}\right]_{\mathrm{o}}$ transients on bath application of $1 \mathrm{~mm}$ glutamate for $10 \mathrm{~s}$ were recorded. Application of glutamate alone would cause action potential firing of neurons, and the whole circuit would be activated. Plasticity on epileptogenesis may include changes not only in the $\left[\mathrm{K}^{+}\right]_{\mathrm{o}}$ clearance mechanisms but also in the synaptic transmission properties as well. Therefore, to focus only on the changes in the $\left[\mathrm{K}^{+}\right]_{\mathrm{o}}$ clearance mechanisms, a Na ${ }^{+}$channel blocker, tetrodotoxin (TTX; $0.5 \mu \mathrm{M}$; catalog \#T8024, Sigma-Aldrich), was dissolved in the perfusate (normal ACSF) to block neuronal action potential firing and prevent action potential-dependent synaptic transmission altogether. To ensure complete block, 15 min of TTX perfusion was applied before the glutamate application. Glutamate bath application in TTX led to a transient increase in $\left[\mathrm{K}^{+}\right]_{\mathrm{o}}$, which was likely to be because of the endogenous $\mathrm{K}^{+}$efflux on activation of ionotropic glutamate receptors and high-affinity glutamate transporters (Hertz et al., 2015). To investigate the effect of epileptiform activity on the $\mathrm{K}^{+}$clearance mechanisms, the first $15 \mathrm{~min}$ of $0 \mathrm{Mg}^{2+}$-Pic solution was perfused in the absence of TTX. TTX was absent during this period to allow action potential firing and epileptiform activity to occur. Afterward, 15 min of a TTX-only solution was applied, followed by the application of glutamate (in the presence of TTX) to measure the transient $\left[\mathrm{K}^{+}\right]_{\mathrm{o}}$ response.

$\mathrm{Na}^{+}$imaging. The sodium-binding benzofuran isophthalate (SBFI)acetoxymethyl ester (AM; catalog \#6212, Setareh Biotech) was loaded into cells in the brain slices by bolus injection, which is described in earlier publications (Stosiek et al., 2003; Gerkau et al., 2019). Wide-field fluorescence imaging was performed using an upright microscope (Fluoview FV1000, Olympus; $60 \times$ water-immersion objective) and a CCD camera (ImagEM, Hamamatsu). Cells were excited alternately at 340 and $385 \mathrm{~nm}$ (Dual-LED, Pritzmatrix), and fluorescence emission $(>478 / 35 \mathrm{~nm})$ was collected at $4 \mathrm{~Hz} . \mathrm{Na}^{+}$influx into a starter astrocyte was induced by its direct electrical stimulation with a theta glass pipette (40 V, $1 \mathrm{~ms}$; Langer et al., 2012). This resulted in a rapid decrease in fluorescent emission excited at $385 \mathrm{~nm}$. Data from some experiments that did not show any fluorescence change of the stimulated cell (indicating failure of electroporation) or a complete loss of cellular fluorescence after the stimulation (indicating permanent loss of membrane integrity) were excluded. For individual regions of interest (ROIs), reflecting somata of SR101-positive astrocytes, the fluorescence ratio $\left(F_{\text {ratio }}=F_{340} / F_{385}\right)$ was calculated and analyzed offline by using AxoGraph and FIJI software. Background correction was performed by subtracting the fluorescence value taken from a concentric annulus positioned around each ROI. Changes in the $\mathrm{Na}^{+}$concentration were expressed as changes in the fluorescence ratio normalized to the baseline (percentage of $\Delta F_{\text {ratio }}$ ).

Generation of KENGE-tetO-Lck-E GFP mice. KENGE-tetO-Lck$\mathrm{E}^{2} \mathrm{GFP}$ mice were generated using Cas9 mRNA and single guide RNA (sgRNA) targeting Actb (sgActb) as previously described (Aida et al., 2015).We generated pTV-Actb-TetO-Lck-E ${ }^{2}$ GFP-poly A targeting vector. The injection mixture was prepared by mixing and diluting Cas9 mRNA $(5 \mathrm{ng} / \mu \mathrm{l})$, sgActb $(2.5 \mathrm{ng} / \mu \mathrm{l})$, and pTV-Actb-TetO-Lck-E ${ }^{2} \mathrm{GFP}$ poly A $(10 \mathrm{ng} / \mu \mathrm{l})$ in $0.1 \mathrm{TE}$ buffer $(10 \mathrm{~mm}$ Tris- $\mathrm{HCl}$, and $0.1 \mathrm{~mm}$ EDTA, $\mathrm{pH}$ 8.0). The methods for the preparation of one-cell stage zygotes and the injection of the above mixture were described previously (Aida et al., 2015). Two-cell stage embryos injected were transferred into pseudopregnant ICR female mice (CLEA Japan). Knock-in mice were screened by PCR with Primestar GXL (Takara) and three different pairs of primers, and were established as a Actb-tetO-Lck-E ${ }^{2}$ GFP knock-in line.

Genotyping. Mlc1-E ${ }^{2}$ GFP mice (Mlc1-tTA::tetO-Lck-E ${ }^{2}$ GFP double transgenic mice) were obtained by crossing Mlc1-tTA mice and tetOLck-E ${ }^{2}$ GFP mice (Sasaki et al., 2012; Tanaka et al., 2012). The following PCR primer sets were used in mouse genotyping: MlcU-657 $\left(5^{\prime}\right.$ AAATTCAGGAAGCTGTGTGCCTGC-3') and mtTA24L (5'CGGAGTTGATCACCTTGGACTTGT-3') for Mlc1-tTA mice; tetOup (5'-AGCAGAGCT CGTTTAGTGAACCGT-3') and intronLow ( $5^{\prime}-$ AAGGCAGGATGATGACCAGGATGT- $3^{\prime}$ ) for tetO-Lck-E ${ }^{2}$ GFP mice. The sizes of the PCR products are $\sim 680$ and $610 \mathrm{bp}$, respectively. Wildtype mice are negative for the above PCR products.

$\mathrm{pH}$ imaging. Intracellular $\mathrm{pH}$ imaging was performed using transgenic mice with astrocyte-specific expression of a $\mathrm{pH}$ sensor (Lck$\mathrm{E}^{2} \mathrm{GFP}$ ). Confocal fluorescence imaging was performed using an upright microscope (FLUOVIEW FV1000, Olympus) equipped with $60 \times$ waterimmersion objective. The soma of an $\mathrm{E}^{2} \mathrm{GFP}$-positive astrocyte was excited at $473 \mathrm{~nm}$. Fluorescence emission from $\mathrm{E}^{2} \mathrm{GFP}$ was separated using a dichroic mirror at $510 \mathrm{~nm}$ and bandpass filtered for detection by the two photomultiplier tubes at $490-540 \mathrm{~nm}$ (Ch1) and $490-590 \mathrm{~nm}$ (Ch2). $z$ stacks of two frames were taken at an interval of $\sim 6 \mathrm{~s} /$ stack for 20 times (total imaging time, $\sim 120 \mathrm{~s}$ ). Sets of $20 z$ stacks were first taken in normal ACSF as the baseline image (Pre). $0 \mathrm{Mg}^{2+}$-Pic solution was then perfused for $15 \mathrm{~min}$ to induce epileptiform activity. The perfusion solution was switched back to normal ACSF, and $20 z$ stacks were taken each at +5 and +10 min after switching back to the normal ACSF.

The averaged relative $\mathrm{pH}$ change for each epoch was calculated as follows. Images were analyzed offline by using AxoGraph and FIJI software. Background corrections of each channel were performed by dividing the baseline fluorescent intensity values obtained from the Pre. For each brain slice, ratio values of the fluorescence intensity $(\mathrm{Ch} 2 / \mathrm{Ch} 1)$ were calculated. For each recording epoch, Ch2/Ch1 values were averaged and normalized to the Ch2/Ch1 values of the Pre (Ch2/Ch1 of Pre $=1$ for each slice). For every condition (control, $\mathrm{OMg}^{2+}$-Pic, and S0859 in $0 \mathrm{Mg}^{2+}-\mathrm{Pic}$ ), these values were normalized to the average values of each epoch obtained from control slices (control $=1$ for each epoch).

Local field potential recordings. Local field potential (LFP) recordings were performed as described previously (Whittington et al., 1997). In brief, a short train of electrical stimuli $(100 \mathrm{~Hz}$ for $100 \mathrm{~ms})$ of the Schaffer collaterals was applied with a bipolar stimulating electrode (catalog \#IMJ2-10H50-0.05, Inter Medical Co., Ltd.) to evaluate the neuronal excitability in acute hippocampal slices [neuronal excitability evaluating stimuli (NEESs)]. NEES-induced neuronal response was recorded with a glass pipette. The recording pipette was filled with normal ACSF (1-5 M $\Omega$ ) and placed in the CA1 pyramidal cell layer. The NEES response was short, lasting less than $\sim 1 \mathrm{~s}$ after the cessation of the stimuli train, which was much shorter than a typical "after discharge (AD)," which is induced by a much more intense stimulation with responses lasting over tens of seconds. NEES responses were recorded 10 times at $10 \mathrm{~s}$ intervals to evaluate the basal neuronal excitability (Pre-epi NEES response). Subsequently, epileptiform activity was induced by a prolonged stimulation of the Schaffer collateral $[100 \mathrm{~Hz}$ for $1 \mathrm{~s}$, which was repeated 20 times at $30 \mathrm{~s}$ intervals; epi stimulation (Epi-stim)]. 
NEES responses were recorded again to evaluate the effect of the epi stimulation on the neuronal excitability [postepilieptic (Post-epi) NEES response]. Both Pre-epi and Post-epi NEES responses were recorded and low-pass filtered at $5 \mathrm{kHz}$ with an Axopatch 200B amplifier (Molecular Devices), and digitized at a sampling frequency of $20 \mathrm{kHz}$ with an analog-to-digital converter (Digidata $1440 \mathrm{~A}$, Molecular Devices). The power spectrum (PS) was calculated for the immediate early phase of the NEES response (95-745 ms after the final stimulation) and was averaged across 8-10 traces. The difference between the Post-epi PS and the Preepi PS was calculated for each slice.

Surgery to prepare rapid hippocampal kindling of mice. C57/BL6J mice $>7$ weeks of age were used in this model. Mice were anesthetized with three types of mixed anesthesia, consisting of $0.75 \mathrm{mg} / \mathrm{kg}$ medetomidine hydrochloride (Domitor, Nippon Zenyaku Kogyo Co., Ltd.), $4 \mathrm{mg} / \mathrm{kg}$ midazolam (Sandoz), and $5 \mathrm{mg} / \mathrm{kg}$ butorphanol tartrate (Vetorphale, Meiji Seika Pharma Co., Ltd.). For the medetomidine reversal after the surgery, $0.75 \mathrm{mg} / \mathrm{kg}$ atipamezole hydrochloride (Antisedan, Zenyaku Kogyo Co., Ltd.) was administered. The anesthetized mouse was mounted on a stereotaxic frame for surgery. For the direct drug application to the brain parenchyma and for electrical stimulation of the hippocampus, a guide cannula and electrode combination was custom made. A guide cannula, such as that used for microdialysis experiments (diameter, $0.5 \mathrm{~mm}$; CX-8, EICOM), was prepared, and two perfluoroalkoxy alkane-coated tungsten wire electrodes with their cut ends exposed (diameter, $0.2032 \mathrm{~mm}$; catalog \#796500, A-M Systems) were adhered to the sides of the guide cannula shaft. This guide cannula/electrode combination was implanted into the right dorsal hippocampus [anteroposterior $(\mathrm{AP})=-2.0 \mathrm{~mm}$; mediolateral $(\mathrm{ML})=1.0 \mathrm{~mm}$; dorsoventral $(\mathrm{DV})=$ $-2.0 \mathrm{~mm}$ ]. Coordinates were based on the mouse brain atlas (Paxinos and Franklin, 2001). For electroencephalography (EEG) recording, two screws were implanted into the skull over the left cerebral cortex. These two stimulation tungsten electrodes and two recording screw electrodes were soldered to a four-pin connector socket, which was attached to the skull with dental cement. Upon the start of experiments, recording wires and stimulation wires were connected to this socket. Rapid kindling experiments started after at least $2 \mathrm{~d}$ of recovery from surgery.

Rapid hippocampal kindling. Mice were placed in a custom-made EEG-video-microdialysis system and allowed to move freely. Kindling stimulations ( $1 \mathrm{~ms}$ pulses, $50 \mathrm{~Hz}$ frequency, $10 \mathrm{~s}$ duration, $5 \mathrm{~V}$ ) were applied 12 times/d at $30 \mathrm{~min}$ intervals with a constant-voltage stimulator (DS2A-Mk.II, Digitimer) for 3 consecutive days. This rapid kindling protocol was similar to the ones used in previous studies (Lothman and Williamson, 1993; Etemadi et al., 2015). EEG signals were amplified (DAM50, WPI), low-pass filtered at $1 \mathrm{kHz}$, and digitized at a sampling frequency of $2 \mathrm{kHz}$ (Micro1401 and Spike2, Cambridge Electronic Design). Behavioral seizures were simultaneously monitored with a video recording system. Animals that did not respond with an $\mathrm{AD}$ to the first stimulation were excluded. For continuous application of S0859 into the brain, a probe with a semipermeable membrane, normally used for microdialysis experiments (diameter, $0.22 \mathrm{~mm}$; CX-I-01, EICOM), was inserted into the guide cannula. Low (physiological) $\mathrm{Ca}^{2+}$ ACSF of the following compositions was used for the microdialysis (in $\mathrm{mM}$ ): 124 $\mathrm{NaCl}, 4 \mathrm{KCl}, 5 \mathrm{HEPES}, 1.1 \mathrm{MgCl}_{2}$, and $1.2 \mathrm{CaCl}_{2}, \mathrm{pH} 7.4, \mathrm{NaOH}$ for titration. This low $\mathrm{Ca}^{2+}$ ACSF with or without $300 \mu \mathrm{M}$ S0859 was perfused through this probe, which allowed administration of the drug permeating through the probe membrane. Although $300 \mu \mathrm{M}$ S0859 was used in the feeding line of the microdialysis probe, the actual effective concentration of S0859 in the brain parenchyma would be much lower. The semipermeable membrane that we used had a recovery rate of $\sim 5-10 \%$ for microdialysis. For example, only $6.7 \%$ of the concentration of norepinephrine [molecular weight $(\mathrm{MW})=169.18$; S0859, $\mathrm{MW}=530.04]$ can be detected passing in through the membrane, when the flow rate is $2 \mu \mathrm{l} / \mathrm{min}$ (see the EICOM website for details concerning the recovery rate of the microdialysis membrane). The drug permeating out through the membrane and entering the brain parenchyma will diffuse to a wider area, but the concentration will become concentrically lower. We assume that the maximum concentration of S0859 would likely be $\sim 10 \%$, which is $\sim 30 \mu \mathrm{M}$. This is less than the concentration used in acute slice experiments $(50 \mu \mathrm{M})$; thus, the adverse effect of $\mathbf{S 0 8 5 9}$ may not be as strong as one may assume from the concentration used in the feeding line $(300 \mu \mathrm{M})$. Compared with pressure application of the drug, the use of the microdialysis probe for drug administration exerts minimal mechanical stress to the brain parenchyma. The flow rate of the perfusion was $2 \mu \mathrm{l} / \mathrm{min}$, and the perfusion started $30 \mathrm{~min}$ before the first kindling stimulation. The perfusion continued until the final stimulation on each day.

Analysis of EEG data. In vivo EEG data were analyzed offline by using AxoGraph. The traces were bandpass filtered between 2 and $20 \mathrm{~Hz}$, and the absolute values were calculated and subsequently integrated. Basal EEG fluctuation produces a linear increase in the integrated traces; thus, a linear fit line of the baseline was subtracted to extract the effect of the hippocampal stimulation. For the "first 2- analysis," the peak amplitude of the integrated traces was calculated for the first and second stimulation and normalized to that of the first stimulation. These values were pooled and were compared between the two groups (control vs S0859) using Student's $t$ test. "AD durations" were manually measured by visual examination of the postfiltered traces. Hippocampal stimulation sometimes resulted in the failure of $\mathrm{AD}$ occurrence. Failure traces were not included for the $\mathrm{AD}$ duration analysis. The "AD occurrence" was manually detected for each stimulation. Daily values of the $\mathrm{AD}$ occurrence were compared between the two groups using the $\chi^{2}$ test. $\mathrm{AD}$ durations, including the failure events, with failure events calculated as zero, were pooled and averaged as "total AD duration." Daily values of the total $\mathrm{AD}$ duration were compared between the two groups using the Mann-Whitney $U$ test.

Data analysis and statistics. Data are presented as the mean \pm SEM. Statistical analysis (Student's $t$ test, Welch's $t$ test, and two-way repeatedmeasures ANOVA followed by Tukey's post hoc test for normally distributed data, $\chi^{2}$ test, or Mann-Whitney $U$ test for non-normally distributed data) was conducted using Excel and OriginPro 8.6J software (OriginLab). For multiple comparison, Student's $t$ test or Welch's $t$ test with Holm correction was used.

\section{Results}

Short-term exposure of epileptiform activity leads to a state prone to more severe hyperactivity. We aimed to understand the cellular mechanisms leading to the exacerbation of epilepsy. To this end, we used electrophysiology and ion concentration recording techniques to analyze the contribution of astrocyte gap junction coupling.

\section{Epileptiform activity acutely impairs $\mathrm{K}^{+}$clearance}

A short-term plasticity model of the exacerbation of epilepsy in acute hippocampal slices of mice was created by exposing a slice to solutions that can induce epileptiform activity (Fig. 1A). Epileptiform activity was induced by $\mathrm{Mg}^{2+}$-free superfusate containing picrotoxin, a $\mathrm{GABA}_{\mathrm{A}}$ receptor antagonist $\left(0 \mathrm{Mg}^{2+}-\mathrm{Pic}\right)$. Current-clamp recordings from pyramidal cells in hippocampal CA1 confirmed the epileptiform-like activity within $15 \mathrm{~min}$ of the $0 \mathrm{Mg}^{2+}$-Pic perfusion ( $n=3$; Fig. $1 B$, top).

We next examined whether $\mathrm{K}^{+}$clearance becomes hindered after the tissue has experienced short-term epileptiform activity. In the presence of TTX, glutamate (Glu) was bath applied for $10 \mathrm{~s}$ to activate the neurons in the slice without making them fire action potentials (Haack et al., 2015; Hertz et al., 2015). Depolarization induced by activating ionotropic glutamate receptors and glutamate transporters would cause extrusion of $\mathrm{K}^{+}$from the cytosol to the extracellular space. As the synaptic and circuitry changes induced by short-term epileptiform activity were not the main focus of this study, TTX was included in this set of experiments to avoid action potentialinduced synaptic transmission from happening. In essence, Glu was used as a means to produce $\mathrm{K}^{+}$release from within the slice. We confirmed that the peak of the transient increase in 
extracellular $\left[\mathrm{K}^{+}\right]_{\mathrm{o}}$ produced by the Glu application was not significantly different between the naive slice and the slice that was pre-exposed to epileptiform activity (see below). The main focus of the article was to study how the tissue recovers from increases in extracellular $\mathrm{K}^{+}$concentration.

A double-barreled $\mathrm{K}^{+}$-selective microelectrode was inserted into the s.r. of CA1 in the hippocampal slice, and several minutes were spent waiting until the readings from the electrode reached a stable baseline. Bath application of $1 \mathrm{~mm}$ Glu (in the presence of TTX) evoked a transient increase in the $\left[\mathrm{K}^{+}\right]_{\mathrm{o}}$ (averaged peak $\Delta\left[\mathrm{K}^{+}\right]_{\mathrm{o}}=2.56 \pm 0.35 \mathrm{~mm}$; Fig. $1 C$, control).

In a separate slice, $0 \mathrm{Mg}^{2+}$-Pic solution was first perfused for $15 \mathrm{~min}$ to produce epileptiform activity in the absence of TTX. Recurrent transient elevations in the $\left[\mathrm{K}^{+}\right]_{\mathrm{o}}$ were recorded during the $0 \mathrm{Mg}^{2+}$. Pic perfusion, which reflect the occurrence of coordinated burst firing of a population of neurons (Fig. $1 B$, bottom; $n=6$ ). Multiple $\left[\mathrm{K}^{+}\right]_{\mathrm{o}}$ transients were observed during the $0 \mathrm{Mg}^{2+}$-Pic application. The half-decay times of these $\left[\mathrm{K}^{+}\right]_{\mathrm{o}}$ transients were compared. $\left[\mathrm{K}^{+}\right]_{\mathrm{o}}$ transients occurring toward the end of the $0 \mathrm{Mg}^{2+}$-Pic application phase tended to decay slower compared with those in the beginning; however, the difference was not statistically different (earlier $\left[\mathrm{K}^{+}\right]_{0}$ transients: half decay time = $0.66 \pm 0.094 \mathrm{~min}, n=6$; later $\left[\mathrm{K}^{+}\right]_{\mathrm{o}}$ transients: half decay time $=1.11 \pm 0.21 \mathrm{~min}, n=6 ; p=0.085$; earlier vs later, Welch's $t$ test).

Subsequently, $1 \mathrm{~mm}$ Glu (in the presence of TTX) was bath applied as in the control (Fig. 1A, bottom, schedule). $\left[\mathrm{K}^{+}\right]_{\mathrm{o}}$ transients in the Post-epi slice were prolonged compared with the control (Fig. 1C, Post-epi). The half decay times of the $\left[\mathrm{K}^{+}\right]_{\mathrm{o}}$ transient were significantly increased (Fig. $1 D$; control, $n=9$; Post-epi, $n=6 ; * p<0.05$, Student's $t$ test). The resting $\left[\mathrm{K}^{+}\right]_{\mathrm{o}}$ before Glu application and the peak $\Delta\left[\mathrm{K}^{+}\right]_{\mathrm{o}}$ in response to Glu application were not significantly different between the two groups (control: resting $\left[\mathrm{K}^{+}\right]_{\mathrm{o}}=2.62 \pm 0.03 \mathrm{~mm}$, peak $\Delta\left[\mathrm{K}^{+}\right]_{\mathrm{o}}=2.56 \pm 0.35 \mathrm{~mm}, n=9$; Post-epi: resting $\left[\mathrm{K}^{+}\right]_{\mathrm{o}}=$ $2.65 \pm 0.03 \mathrm{~mm}$, peak $\Delta\left[\mathrm{K}^{+}\right]_{\mathrm{o}}=3.36 \pm 0.64 \mathrm{~mm}, n=6$; $p=0.49$ and 0.26 , control vs Post-epi for resting $\left[\mathrm{K}^{+}\right]_{\mathrm{o}}$ and peak $\Delta\left[\mathrm{K}^{+}\right]_{\mathrm{o}}$, Student's $t$ test). Slowing of glutamate transporter kinetics could explain the slowed $\left[\mathrm{K}^{+}\right]_{\mathrm{o}}$ transient decay; however, that would likely result in a larger peak amplitude of the $\Delta\left[\mathrm{K}^{+}\right]_{\mathrm{o}}$. Therefore, the glutamate uptake response to glutamate application was not likely to be largely different between control and Post-epi slices.

\section{Gap junctions become uncoupled}

Hindrance of extracellular $\mathrm{K}^{+}$clearance in Post-epi slices could be because of the acute uncoupling of astrocyte gap junctions. Therefore, we next examined the effect of epileptiform activity on the degree of gap junction coupling between astrocytes (Fig. 2A). We were interested in changes that were induced with only a short time exposure $(15 \mathrm{~min})$ of epileptiform activity. Fluorescent dyes can take tens of minutes to hours to diffuse intercellularly; thus, evaluating the gap junctional coupling based on dye-coupling experiments was unrealistic. In addition, gap junctions may not become fully closed, and the permeability of differently sized molecules through
B CA1 pyramidal neuron, l-clamp rec.

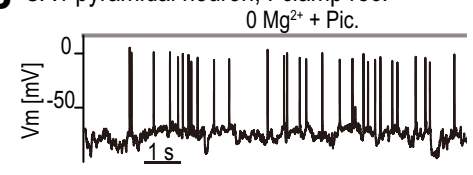

CA1 s.r., $\left[\mathrm{K}^{+}\right]_{0}$ rec. $\quad 0 \mathrm{Mg}^{2+}+$ Pic.

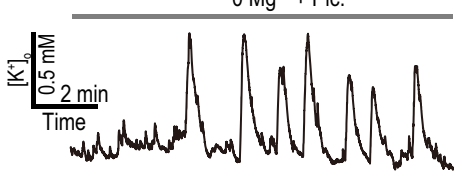

D

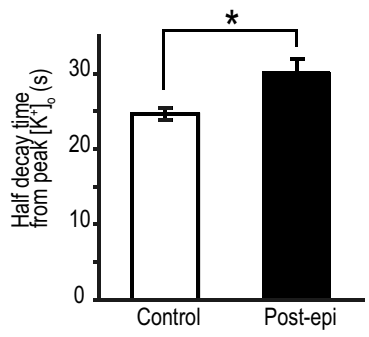

Glu

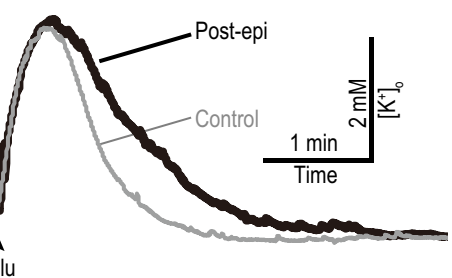

Figure 1. $\mathrm{K}^{+}$clearance is impaired after short-term epileptiform activity. $\boldsymbol{A}, \mathrm{Top},\left[\mathrm{K}^{+}\right]_{0}$ values were recorded from the CA1 s.r. in the hippocampus with a $\mathrm{K}^{+}$-sensing double-barreled microelectrode. Bottom, (bottom). Current-clamp recordtion (similar results from $n=3$ slices). With the $\mathrm{K}^{+}$-sensing electrode positioned in the CA1 s.r., multiple from peak of the $\left[\mathrm{K}^{+}\right]_{0}$ transient in response to Glu application (control, $n=9$; Post-epi, $n=6 ; * p<0.05$, tudent's $t$ test). Error bars indicate the SEM. $0 \mathrm{Mg}^{2+}$-Pic, $\mathrm{Mg}^{2+}$-free normal ACSF supplemented with 100 $\mu \mathrm{m}$ Pic. $V_{\mathrm{m}}$, membrane potential.

connexins may be differentially regulated (Nicholson et al., 2000). Tracking the diffusion of $\mathrm{K}^{+}$ions themselves would be ideal; however, the intracellular $\mathrm{K}^{+}$concentration $\left(\left[\mathrm{K}^{+}\right]_{\mathrm{i}}\right)$ is normally high, and detecting small concentration changes in a high background is extremely difficult. Therefore, we decided to use $\mathrm{Na}^{+}$ions as a dynamic tracer of intercellular diffusion of small cations through gap junctions (Langer et al., 2012; Wang et al., 2020). Concentrations of $\left[\mathrm{Na}^{+}\right]_{\mathrm{i}}$ are normally low. $\left[\mathrm{Na}^{+}\right]_{\mathrm{i}}$ has been successfully recorded with a specific fluorescence indicator dye (SBFI; Minta and Tsien, 1989; Rose and Ransom, 1996). The mobility of $\mathrm{K}^{+}$and $\mathrm{Na}^{+}$ in aqueous solution is very similar, and the permeability of $\mathrm{K}^{+}$and $\mathrm{Na}^{+}$through connexins has also been reported to be similar (Wang and Veenstra, 1997).

SR101 was first loaded in the acute slice and SBFI-AM was subsequently loaded (Fig. 2B). As SR101 is selectively taken up by astrocytes, the fluorescence of SR101 was used as a positive marker of astrocytes (Nimmerjahn et al., 2004). A glass pipette was directly positioned on top of an identified astrocyte cell body, and this cell was electrically stimulated (40 V, $1 \mathrm{~ms}$; Langer et al., 2012). Immediately after a single stimulation, the fluorescence emission evoked by excitation at $385 \mathrm{~nm}$ decreased, while the emission evoked by excitation at $340 \mathrm{~nm}$ remained unchanged. This resulted in a transient change in the $F_{\text {ratio }}$ from the baseline, $\Delta F_{\text {ratio }}\left(\Delta F_{\text {ratio }}=\right.$ $\Delta F_{340} / \Delta F_{385}$; Fig. $\left.2 C\right)$. An increase in the $\Delta F_{\text {ratio }}$ indicates an increase in the $\left[\mathrm{Na}^{+}\right]_{\mathrm{i}}$. The initial cell that was directly stimulated was termed the "starter cell." $\Delta F_{\text {ratio }}$ was observed 

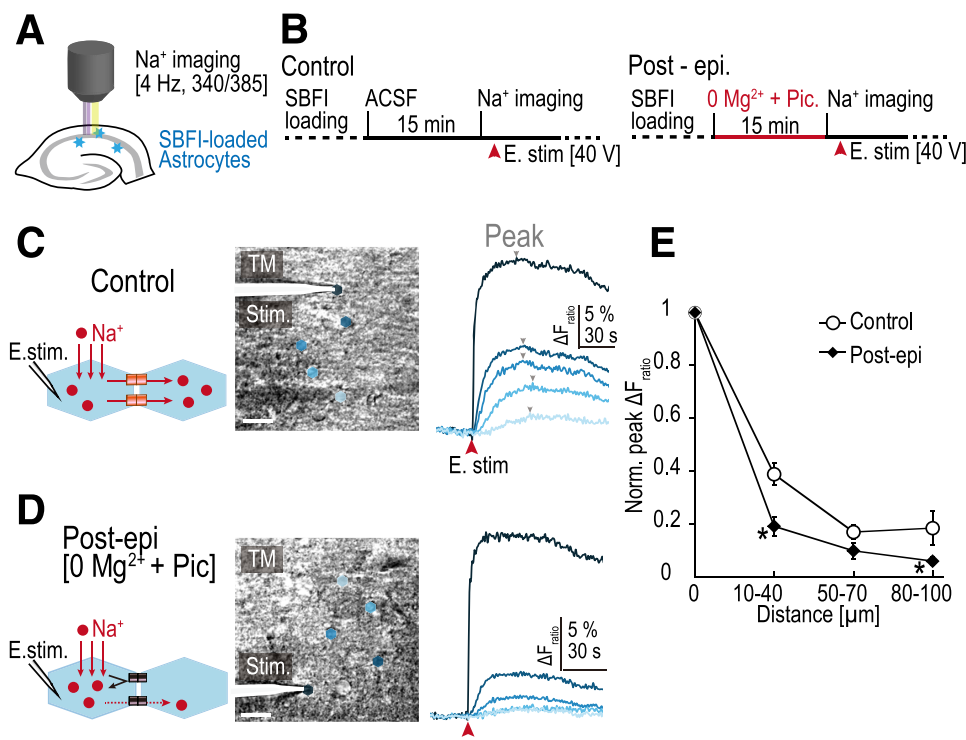

Figure 2. Gap junction uncoupling after short-term epileptiform activity. $\boldsymbol{A}$, Intracellular $\mathrm{Na}^{+}$concentration of hippocampal astrocytes was imaged using a fluorescent $\mathrm{Na}^{+}$indicator (SBFI-AM). $\boldsymbol{B}$, Schedule of the experimental procedures. In control slices (left), electrical stimulation (E. stim; $1 \mathrm{~ms}, 40 \mathrm{~V}$ ) to the starter cell was applied after $15 \mathrm{~min}$ of ACSF perfusion. For the Post-Epi experiments, $\mathrm{OMg}^{2+}$-Pic was applied for $15 \mathrm{~min}$ followed by the $\mathrm{Na}^{+}$ imaging of the response to $\mathrm{E}$. stim in normal ACSF (right, Post-epi). C, Left, Diagram of the experiment. Middle, A transmission image (TM) from the recorded slice. Locations of the astrocytes are shown as color polygons. Directly stimulated astrocyte (starter cell) is at the tip of the electrode. Scale bars, $20 \mu \mathrm{m}$. Right, Time course of the fluorescent changes corresponding to the changes in the intracellular $\mathrm{Na}^{+}$concentration. $F_{\text {ratio }}$ from the baseline $\left(=\Delta F_{340} / \Delta F_{385}\right)$ was calculated for each astrocyte. Arrowheads (gray), peaks of $F_{\text {ratio. }}$ In control, $\mathrm{Na}^{+}$increase was observed in astrocytes that are distant from the starter cell. $\boldsymbol{D}$, In Post-epi slices, $\mathrm{Na}^{+}$increase was largely confined to the starter cell and $\mathrm{Na}^{+}$increase in the distant astrocytes was minimal. $\boldsymbol{E}$, Peak $\Delta F_{\text {ratio }}$ was measured for each astrocyte and normalized to the peak $\Delta F_{\text {ratio }}$ of the starter cell and plotted against the distance of the astrocyte from the starter cell in control and in Post-epi slices. Values from each cell were pooled and averaged for the distances of $10-40,50-70$, and $80-100 \mu \mathrm{m}$ from the starter cell. Peak $\Delta F_{\text {ratio }}$ was reduced in multiple distance categories, indicating that $\mathrm{Na}^{+}$spreads less in slices that had been exposed to prior epileptiform activity (control, $n=22$, 23,4 ; Post-epi, $n=11,13,8$ for each distance, respectively; $* p<0.05$, Welch's $t$ test with Holm correction). Error bars indicate SEM.

in astrocytes neighboring the starter cell as well, indicating that intercellular diffusion of $\mathrm{Na}^{+}$occurs from the starter cell to the neighboring astrocytes via gap junctions (Fig. 2C). The peak of $\Delta F_{\text {ratio }}$ in individual cells gradually decayed over the distance from the starter cell (Fig. 2E).

The amount of initial $\mathrm{Na}^{+}$loading into the starter cell varied from trial to trial. We compared the amount of gap junctional spread of $\mathrm{Na}^{+}$when the initial $\mathrm{Na}^{+}$loading was high $(>50 \%$ change in $\left.\Delta F_{\text {ratio }}\right)$ with when it was low $(<50 \%)$. The relative diffusion of $\mathrm{Na}^{+}$into the nearby surrounding astrocytes was not affected by the initial $\mathrm{Na}^{+}$loading amount (for distances 10-40 and $50-70 \mu \mathrm{m}, p=0.17$ and $p=0.08$, respectively; and between the high initial $\Delta F_{\text {ratio }}$ group, $n=5$ and $n=6$, and the low initial $\Delta F_{\text {ratio }}$ group, $n=17$ and $n=17$, respectively; Student's $t$ test). Therefore, as long as the initial $\mathrm{Na}^{+}$loading is above the threshold for SBFI fluorescence detection, the precise amount of the initial $\mathrm{Na}^{+}$does not appear to affect the relative intercellular diffusion.

Similar experiments were performed in slices that were preexposed to a short-term epileptiform activity with the $0 \mathrm{Mg}^{2+}$-Pic perfusion (Post-epi; Fig. $2 B$, right schedule). The initial peak $\Delta F_{\text {ratio }}$ of the stimulated astrocytes was similar between control and Postepileptic slices (control, $n=17$; Post-epi, $n=24 ; p=0.90$; Student's $t$ test). The peak $\Delta F_{\text {ratio }}$ decreased over distance, as in the control slices, but the decrease was more apparent (Fig. 2D). Compared with the control, the normalized peak $\Delta F_{\text {ratio }}$ was significantly reduced in multiple intercellular distances from the starter cell (control: $n=22,23,4$; $\mathrm{SD}=0.20,0.12,0.13$; Post-epi: $n=11,13,8$; SD $=0.18,0.10,0.05$ for each interval, 10-40, 50-70, 80-100 $\mu \mathrm{m}$, respectively; $* p<0.05$, Welch's $t$ test; Fig. $2 E$ ). This result indicates that intercellular diffusion of a small cation, $\mathrm{Na}^{+}$, is decreased after shortterm epileptiform activity, which suggests that gap junction uncoupling occurred between astrocytes.

\section{Intracellular alkalization via activation of $\mathrm{Na}^{+} / \mathrm{HCO}_{3}{ }^{-}$cotransporter}

We next sought to unveil the mechanisms connecting epileptiform activity and gap junction uncoupling in astrocytes. It has been reported that astrocytes respond to epileptiform activity with intracellular alkalization (Chesler and Kraig, 1987; Grichtchenko and Chesler, 1994; Raimondo et al., 2016). It has also been reported that opening of connexins is sensitive to changes in intracellular $\mathrm{pH}$ (González-Nieto et al., 2008), as well as in their phosphorylation (Urschel et al., 2006). Based on this logic, we assumed that intracellular $\mathrm{pH}$ changes in astrocytes induced by epileptiform activity could lead to gap junction uncoupling. To examine whether the $\mathrm{pH}$ change does indeed occur in response to epileptiform activity and to determine the mechanisms underlying such $\mathrm{pH}$ shifts, $\mathrm{pH}$ imaging was performed in acute slices.

A genetic $\mathrm{pH}$ sensor ( $\mathrm{E}^{2} \mathrm{GFP}$; Bizzarri et al., 2006) was conjugated with a membrane-tethering domain, Lck, to generate Lck-E ${ }^{2}$ GFP to monitor $\mathrm{pH}$ changes especially in the submembrane domain, a similar strategy to the LckGCaMP3 for $\mathrm{Ca}^{2+}$ (Shigetomi et al., 2010). Transgenic mice were created with tetO promoter, leading to the expression of the Lck-E ${ }^{2}$ GFP. These mice were crossed with mice expressing tetracycline transactivator (tTA) under astrocyte-specific promoter Mlc1 (Mlc1-tTA mouse; Tanaka et al., 2012), resulting in bigenic mice expressing Lck-E ${ }^{2}$ GFP specifically in astrocytes. Not all astrocytes in the brain expressed Lck$E^{2} \mathrm{GFP}$, and in the hippocampal CA1 s.r., expression was sparsely observed, which allowed examination of individual cells (Fig. 3A, left). After exposing the slice to $0 \mathrm{Mg}^{2+}$-Pic for $15 \mathrm{~min}$, astrocytes became significantly alkalized relative to the control (control, $n=5$; Post-epi, $n=11 ; * * p<0.01$, two-way repeated-measures ANOVA followed by Tukey's post hoc test; Fig. $3 A$, right). This alkaline shift lasted for at least 10 min after $0 \mathrm{Mg}^{2+}$-Pic perfusion (time after $0 \mathrm{Mg}^{2+}$-Pic perfusion: control: $5 \mathrm{~min}, n=5 ; 10 \mathrm{~min}, n$ = 5; Post-epi: $5 \mathrm{~min}, n=11 ; 10 \mathrm{~min}, n=11$ for; $p=0.0019$, 0.0027; Student's $t$ test).

The electrogenic NBC is known to switch to the inward transport mode on depolarization of astrocytes, resulting in an influx of both $\mathrm{Na}^{+}$and $\mathrm{HCO}_{3}{ }^{-}$. Since $\mathrm{HCO}_{3}{ }^{-}$is an alkaline ion, inward NBC activity could account for the intracellular alkalization of astrocytes (Chesler and Kraig, 1987; Grichtchenko and Chesler, 1994; Raimondo et al., 2016). S0859 is a compound that works as an NBC blocker. Astrocyte alkalization in response to epileptiform activity was examined in the presence of $50 \mu \mathrm{M}$ S0859. S0859 significantly reduced the alkaline $\mathrm{pH}$ shifts in response to 
short-term epileptiform activity induced by $0 \mathrm{Mg}^{2+}$-Pic (Post-epi, $n=11$; Post-epi + S0859, $n=10 ; * * p<0.01$, two-way repeated-measures ANOVA followed by Tukey's post hoc test; Fig. $3 B)$. This result shows that the astrocyte alkalization induced by short-term epileptiform activity was mediated, at least in part, by the actions of NBC.

\section{Intracellular alkalization induces gap junction uncoupling}

Intracellular alkalization could lead to gap junction uncoupling. To test this idea, intracellular alkalization was artificially induced by the application of $\mathrm{NH}_{4} \mathrm{Cl}$ (Eto et al., 2003; Kelly et al., 2009). It has been established that, immediately after $\mathrm{NH}_{4} \mathrm{Cl}$ bath application, intracellular alkalization occurs. However, this alkalization is followed by acidifications, often after $\mathrm{NH}_{4} \mathrm{Cl}$ removal. To confirm whether this intracellular $\mathrm{pH}$ shift could be replicated in our study, we performed $\mathrm{pH}$ imaging using brain slices from the Mlc1-tTA::tetO-Lck-E ${ }^{2}$ GFP mice. In accordance with the previous reports, on $20 \mathrm{~mm}$ $\mathrm{NH}_{4} \mathrm{Cl}$ bath application, astrocytes indeed became alkalized compared with the baseline $\left(n=2, \Delta F_{\text {ratio }}=1.05 \pm 0.02\right.$; normalized to baseline). After $8-10 \mathrm{~min}$ of $\mathrm{NH}_{4} \mathrm{Cl}$ perfusion, the bath solutions were switched back to the normal ACSF without $\mathrm{NH}_{4} \mathrm{Cl}$. An immediate rebound acidification was also observed with the removal of $\mathrm{NH}_{4} \mathrm{Cl} \quad(n=2$, normalized $\Delta F_{\text {ratio }}=0.85 \pm 0.004$; normalized to baseline) . Therefore, the $\mathrm{Na}^{+}$imaging to evaluate the extent of gap junction coupling was performed in the presence of $\mathrm{NH}_{4} \mathrm{Cl}$ within $8 \mathrm{~min}$ from the start of perfusion to ensure intracellular alkalization, not acidification.

Compared with the control, the normalized peak $\Delta F_{\text {ratio }}$ was significantly reduced in multiple intercellular distances from the starter cell in the presence of $20 \mathrm{mM} \mathrm{NH}_{4} \mathrm{Cl}$ in ACSF (control: $n=22,23,4$; $\mathrm{SD}=0.20,0.12,0.13$; Alkalization: $n=13,13$, 13 ; $\mathrm{SD}=0.09,0.10,0.06$; for each interval: $10-40,50-70,80-$ $100 \mu \mathrm{m}$, respectively; $* p<0.05$, $* * * * p<0.0001$, Welch's $t$ test; Fig. $3 C$, top, $D$, left). As mentioned above, the amount of initial $\mathrm{Na}^{+}$loading to the starter cell varied from trial to trial; however, the relative intercellular $\mathrm{Na}^{+}$diffusion did not appear to depend significantly on the initial $\mathrm{Na}^{+}$loading. Although the data taken in $\mathrm{NH}_{4} \mathrm{Cl}$ condition happened to have a relatively smaller initial peak $\Delta F_{\text {ratio }}$ compared with the control on average (control, $n=17$; Alkalization, $n=12 ; p<0.05$, Welch's $t$ test), the low diffusion of $\mathrm{Na}^{+}$in $\mathrm{NH}_{4} \mathrm{Cl}$ condition is likely not because of the low initial $\mathrm{Na}^{+}$amplitude. These data suggest that gap junction uncoupling occurs in response to intracellular alkalization.

We have shown above that intracellular alkalization of astrocytes in response to epileptiform activity could be partially inhibited with the application of S0859, a blocker of NBC (Fig. 3B). Therefore, we examined whether the gap junction uncoupling could also be prevented with the application of S0859. After the slice had been exposed to epileptiform activity with $0 \mathrm{Mg}^{2+}-\mathrm{Pic}$, gap junctions between astrocytes became uncoupled (Figs. 2D, $E, 3 D$, right, Post-epi). However, with the application of S0859
B
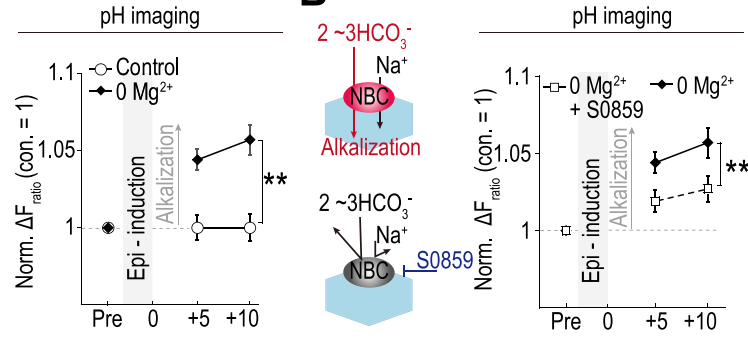

$\mathrm{Na}^{+}$imaging

D

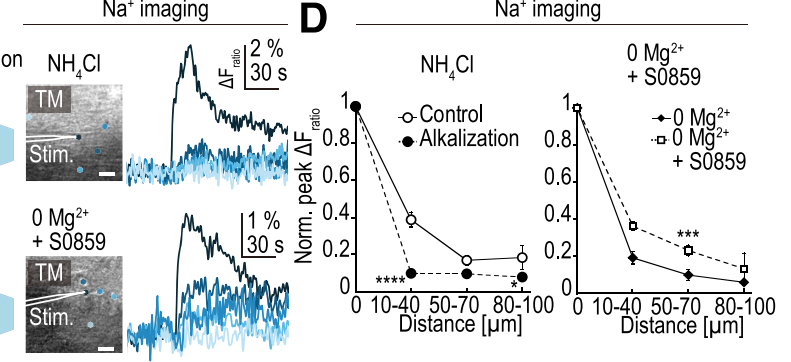

Figure 3. Intracellular alkalization and gap junction uncoupling on epileptiform activity. $\boldsymbol{A}$, Left, Diagram of the experimental setup (top) and a fluorescent image of $E^{2} G F P$ expression the bigenic mice, Mlc1-tTA::tet0-Ick- $E^{2} G F P$.

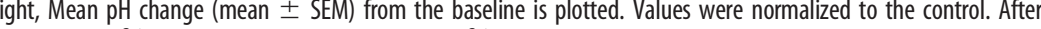
control at both +5 and +10 min time points (control, $n=5 \cdot 0 \mathrm{Mg}^{2+}$-Pic $n=11 * * * p<0.01$, two-way repeatedFig. $3 A, n=11$. 50859 in $\mathrm{OMg}^{2+}$-Pic $n=10$; **p $<0.01$ two-way repeated-measures ANOVA followed by Tukey's post hoc test). C, Gap junction coupling evaluated by the $\left[\mathrm{Na}^{+}\right]_{\mathrm{i}}$ imaging in astrocytes. Top panels,

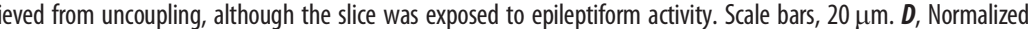
ratio plotted against the distance from the starter cell in alkalized and 50859 conditions. Gap junction cou$\mathrm{H}_{4} \mathrm{Cl}, n=13,13,13$ for each interval, 10-40, 50-70, 80-100 $\mu \mathrm{m}$, respectively; $* p<0.05$, **** $* 0.0001$, Welch's $t$ test with Holm correction). Even when the slice was exposed to $\mathrm{OMg}^{2+}$-Pic solution, if the solution was supplemented with S0859, the gap junction was relieved from uncoupling $\left(\mathrm{MMg}^{2+}-\mathrm{Pic}\right.$, same data as in Fig. $2 E$, $n=11,13,8 ;$; S0859 in $0 \mathrm{Mg}^{2+}$-Pic, $n=26,13,3$ for each interval, respectively; $* * * p<0.001$, Welch's $t$ test).

in the superfusate, the normalized peak $\Delta F_{\text {ratio }}$ was significantly increased at an intercellular distance of $50-70 \mu \mathrm{m}$ from the starter cell (Post-epi: $n=11,13,8 ; \mathrm{SD}=0.18,0.10,0.05$; Post-epi + S0859: $n=26,13,3 ; \mathrm{SD}=0.14,0.09,0.13$; for each interval, $10-40,50-70,80-100 \mu \mathrm{m}$, respectively; $* * * p<0.001$, Welch's $t$ test; Fig. $3 C$, bottom, $D$, right). In these S0859 datasets, again, the average amount of initial $\mathrm{Na}^{+}$loading happened to be low (Post-epi, $n=24$; Post-epi + S0859, $n=15$; $p<0.05$; Welch's $t$ test), which was similar to the $\mathrm{NH}_{4} \mathrm{Cl}$ condition. In contrast to the above $\mathrm{NH}_{4} \mathrm{Cl}$ condition, however, the diffusion was high. This also supports the idea that $\mathrm{Na}^{+}$diffusion is not dependent on the amount of initial $\mathrm{Na}^{+}$loading but is dependent on the astrocyte gap junction coupling, which is likely to be controlled by the intracellular $\mathrm{pH}$. This result suggests that, when astrocyte alkalization in response to epileptiform activity is prevented, astrocyte gap junctions become relieved from uncoupling. Previous reports suggest that the gap junction coupling is not linearly related to the intracellular $\mathrm{pH}$ (Swietach et al., 2007). This nonlinear relationship likely underlies the fact that changes in gap junction coupling were nearly completely blocked (Fig. $3 C, D$ ), but the $\mathrm{pH}$ change was only partially blocked with S0859 (Fig. 3B). 
A

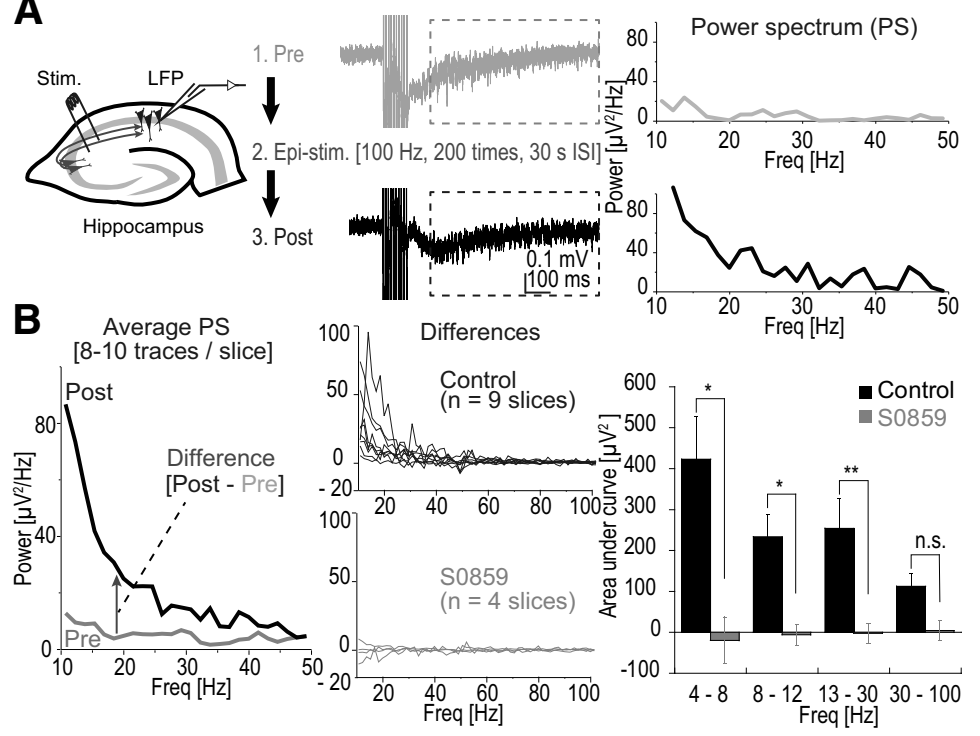

Figure 4. Development of hyperactivity was prevented by $\mathbf{5 0 8 5 9 .}$ A, Left, Schaffer collaterals were electrically stimulated and the LFP was recorded with an electrode placed in the CA1 region. NEESs were applied and NEES-induced response was recorded after each train simulation. A train consisted of $100 \mathrm{~Hz}$ for $100 \mathrm{~ms}$, which was repeated at $10 \mathrm{~s}$ intervals for 10 times. NEES responses were recorded in $\mathrm{Mg}^{2+}$-free ACSF to ensure short-lasting (less than $\sim 1 \mathrm{~s}$ ) response to NEES. Epileptiform activity was induced with a more intense stimulation, also in $\mathrm{Mg}^{2+}$-free ACSF (Epi-stim, $100 \mathrm{~Hz}$ for $1 \mathrm{~s}$, which was repeated 20 times at $30 \mathrm{~s}$ intervals). NEES responses were recorded before (Pre-epi NEES) and after (Post-epi NEES) the Epi-stim. Middle, Traces represent NEES responses of Pre-epi (gray) and Post-epi (black) from the same slice. Right, PS of the NEES response was calculated for the time window between 95 and $745 \mathrm{~ms}$ after the final stimulation for the single traces shown in the middle panel. Within the range shown, power increased in all frequencies once the slice was exposed to epileptiform activity. $\boldsymbol{B}$, Left, PS was calculated for each of the traces recorded from a single slice and subsequently averaged. Difference between Post-epi NEES and Pre-epi NEES was calculated. Middle panels, PS differences are plotted against the frequency for recordings from all nine slices in control (black). Positive values indicate that the power of the NEES response became larger especially in the lower frequency range $(\sim 10-50 \mathrm{~Hz})$. In contrast, when 50859 (gray) was applied, a power increase after epileptiform activity was not observed. Right, Bar graphs showing the mean \pm SEM AUCS of PS differences from 4 to 8,8 to 12,13 to 30, and 30 to $100 \mathrm{~Hz}$, respectively. An increase in the AUCs was observed epileptiform activity in control, whereas such an increase totally abolished in the presence of 50859 (control, $n=9$; S0859, $n=4 ; * p<0.05$, **p $<0.01$; n.s., not significant, Welch's $t$ test). ISI, Interstimulus interval; Freq, frequency.

\section{Neuronal excitability increase was prevented by inhibition of alkalization}

Following epileptiform activity, neuronal excitability is known to increase. Our results shown above indicate that only tens of minutes of short-term epileptiform activity lead to alkalization of astrocytes, which leads to gap junction uncoupling and to an attenuated clearance of $\left[\mathrm{K}^{+}\right]_{\mathrm{o}}$ from the extracellular space. This delay in the $\left[\mathrm{K}^{+}\right]_{\mathrm{o}}$ clearance could be the underlying mechanisms for the early epileptogenesis. Therefore, it may be possible to prevent the exacerbation of epilepsy by suppressing the alkalization of astrocytes to epileptiform activity.

To examine this possibility, first, a short train of stimuli $(100 \mathrm{~Hz}$ for $100 \mathrm{~ms})$ of the Schaffer collaterals was applied to evaluate the neuronal excitability in acute hippocampal slices (i.e., NEESs) and LFP recordings were analyzed (Fig. 4A). In normal ACSF, this short train of stimulation failed to induce a sizable response, which can outlast the duration of the stimuli (data not shown), probably because of the fact that the circuitry of the hippocampus was partially cut from the slicing procedure. Therefore, for all recording sessions for Figure $4, \mathrm{Mg}^{2+}$-free ACSF was always used to ensure a short-lasting (less than $\sim 1$ s) response to NEES, which could be analyzed without the interference of the artifact. It should be mentioned that, even in $\mathrm{Mg}^{2+}$-free ACSF, without picrotoxin, spontaneous continuous epileptiform activity did not occur. First, the NEES response was recorded as a control (Preepi NEES response; $100 \mathrm{~Hz}$ for $100 \mathrm{~ms}$, which was repeated at $10 \mathrm{~s}$ intervals for 10 trials). Then, epileptiform activity was induced with a prolonged Schaffer collateral stimulation that lasted for $10 \mathrm{~min}$ total (Epi-stim; $100 \mathrm{~Hz}$ for $1 \mathrm{~s}$, which was repeated 20 times at $30 \mathrm{~s}$ intervals). After this epileptiform activity, the NEES response was recorded again to evaluate the changes in the neuronal excitability (Post-epi NEES response).

Pre-epi and Post-epi NEES responses were analyzed and the PS density was calculated. At nearly all of the frequency bands within the range of $10-50 \mathrm{~Hz}$, Postepi power was larger than the Pre-epi power (Fig. 4B, left). The difference in the Post-epi and Pre-epi PS density graphs was taken as a measure of NEES response intensification induced by epileptiform activity. In all nine slices tested, the NEES response intensification was apparent. However, when S0859 was applied during the Epi-stim phase, such an increase in the PS density was not observed (Fig. $4 B$, middle bottom). The area under the curve (AUC) of the PS density was calculated for each frequency division shown in Figure $4 B$ (right). The difference in the AUC was significant for most frequency divisions (control, $n=9$; $50 \mu \mathrm{M} \mathrm{S0859,} n=4 ; * p<$ $0.05, * * p<0.01$ Welch's $t$ test; Fig. $4 B$, right). This result indicates that the blockade of NBC suppresses the development of neuronal excitability in response to short-term $10 \mathrm{~min}$ exposure to epileptiform activity.

In vivo rapid kindling was inhibited with NBC blockade

After cessation of a long train (more than several seconds) of electrical stimulation of the hippocampus in vivo, a period of increased neuronal activity is observed that can last for many seconds. This activity is referred to as stimulus-induced AD (Goddard et al., 1969). Following repeated exposure to ADinducing stimuli, AD becomes intensified. This intensification of hyperactivity is referred to as "kindling" and such a plastic change of the brain is thought to be associated with the exacerbation of epilepsy (Goddard, 1983; Lothman and Williamson, 1993).

As shown above, the development of hyperexcitability was suppressed by application of a NBC blocker, S0859. We further explored the possibility that the exacerbation of epilepsy can be prevented by S0859. To examine this, a rapid hippocampal kindling model was adopted to perform experiments in vivo (Fig. $5 A, B$; electrical stimulation with a bipolar electrode implanted in the hippocampus, $50 \mathrm{~Hz}$ for $10 \mathrm{~s}, 30 \mathrm{~min}$ interstimulus interval, 12 stimulations/d for $3 \mathrm{~d}$ ). Stainless screw electrodes were used for cortical EEG recordings, and ADs were examined from these recordings. A probe with a semipermeable membrane, such as used for microdialysis experiments, was inserted into the hippocampus via the guide cannula (Fig. $5 A, B$ ). During the recording 
sessions, either the low (physiological) $\mathrm{Ca}^{2+}$ in vivo ACSF or the low $\mathrm{Ca}^{2+}$ in vivo ACSF supplemented with $300 \mu \mathrm{M}$ S0859 was continuously administered through this probe. A relatively high concentration of S0859 was used in this experiment because the actual effective drug concentration reaching the brain tissue would likely be reduced after going through the semipermeable membrane of the microdialysis probe. As the recovery rate of this probe is $\sim 5-10 \%$, maximum concentration reached in the brain parenchyma is likely to be $<30 \mu \mathrm{M}$ (see Materials and Methods).

In control conditions, the intensity of the $\mathrm{AD}$ elicited by the second train of stimuli tended to increase compared with the first train (Fig. 5C, left top). To quantify the intensity of the $\mathrm{AD}$, first, the absolute value of the raw EEG trace was taken and then an integral of the value was calculated. The basal EEG has constant noise; thus, the raw EEG trace fluctuates between positive and negative values. Therefore, when an absolute value is taken, constant fluctuation of only the positive values would be obtained. Accumulated integral of these values would result in a continuous increase, which would be approximately linear along the time axis. Stimulus-induced AD would add larger fluctuation to the EEG trace on top of the basal fluctuation. To evaluate the fluctuation increase induced by stimulusinduced $\mathrm{AD}$, the linear increase in the absolute baseline integral was subtracted from the absolute EEG integral increase and shown as a graph (Fig. $5 C$, right). In controls, compared with the first $\mathrm{AD}$, the second $\mathrm{AD}$ tended to have a larger peak integrated amplitude. On the contrary, in the presence of S0859, an $\mathrm{AD}$ increase between the first and second train stimulus was not apparent and, actually, the AD intensity, rather, often decreased (Fig. 5C, bottom panels). The $\mathrm{AD}$ intensity from the first and the second stimulations was compared between the two groups (Fig. 5D). The peak ratio (second peak/first peak) of the $\mathrm{AD}$ intensity was significantly decreased by $\$ 0859$ administration compared with controls ( $n=6$ animals each; $* p<0.05$, Student's $t$ test; Fig. 5D, left). This result shows that exposure to a single epileptiform activity leads to the development of hyperactivity in vivo, as in slices. It also shows that this short-term development can be prevented with NBC blockade with S0859.

To further examine the effects of S0859, we observed the AD occurrence rate and the $\mathrm{AD}$ durations for the whole $3 \mathrm{~d}$ kindling period. $\mathrm{AD}$ was produced in response to nearly every stimulus train in control conditions, whereas the occurrence of the $\mathrm{AD}$ rapidly declined with continuous administration of S0859 (during the $6 \mathrm{~h}$ of recording time). By day 3, no $\mathrm{AD}$ was evoked in

c

D
A Inhibition of rapid kindling

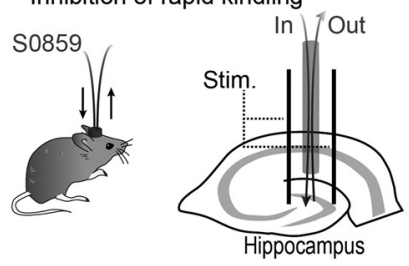

B

Rapid hippocampal kindling

[50 Hz for $10 \mathrm{~s}, 30 \mathrm{~min} I \mathrm{SI}, 12 \mathrm{stim} / \mathrm{day}]$

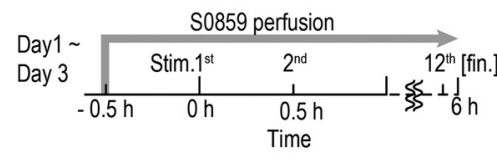

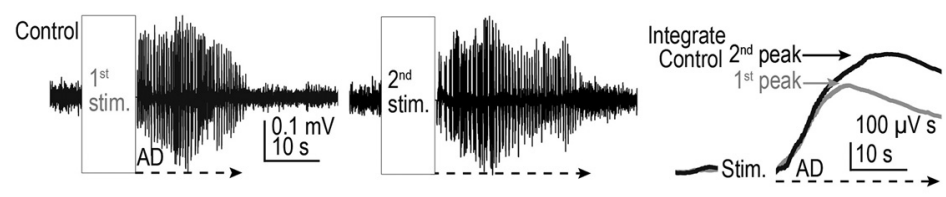
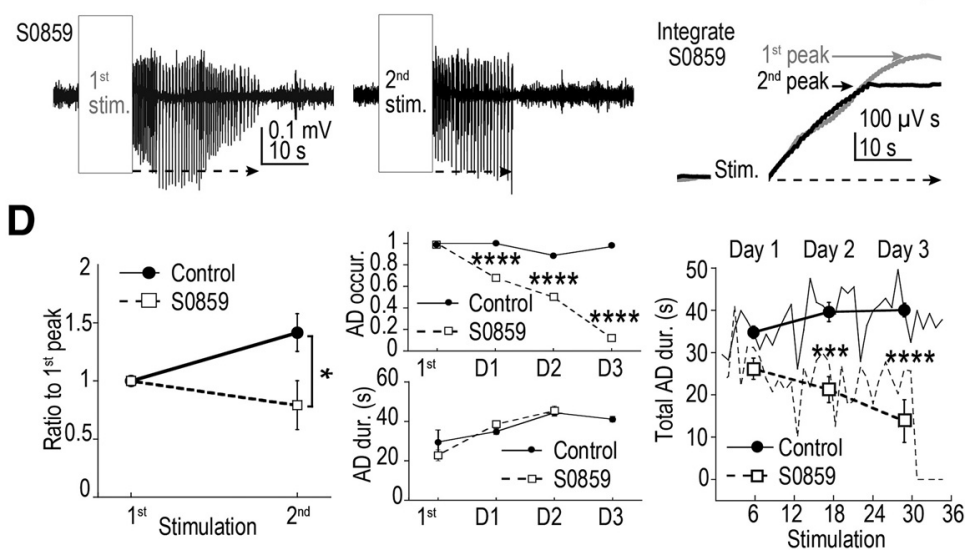

Figure 5. NBC blocker suppressed in vivo rapid hippocampal kindling. $\boldsymbol{A}$, Diagram of the method for intrahippocampal application of 50859 during rapid kindling. A microdialysis probe with semipermeable membrane was used, and ACSF continuously flowed through the probe (gray). When $\mathbf{5 0 8 5 9}$ was added to the ACSF, S0859 would be directly applied to the brain parenchyma by permeating through the tip membrane. Electrical stimulations to the hippocampus were delivered between the two implanted electrodes (black bars shown as Stim.). $\boldsymbol{B}$, Experimental time courses of rapid hippocampal kindling. ACSF or ACSF supplemented with $300 \mu \mathrm{m}$ S0859 was applied through the probe 30 min before the first stimulation. The solution application lasted for $\sim 6 \mathrm{~h}$ until end of the 12th stimulation. A train stimulus consisted of $1-$ ms-duration pulses at $20 \mathrm{~ms} \mathrm{ISI}(50 \mathrm{~Hz}) 500$ times $(10 \mathrm{~s})$, which was repeated at $30 \mathrm{~min}$ interval 12 times/d. Approximately $6 \mathrm{~h}$ of such experiments were repeated for 3 consecutive days. C, Top, Stimulation-induced ADs were often more severe for the second (black) stimulation compared with the first one (gray) in control. Arrows represent the duration of ADs. Bottom, This acute increase in the severity of the stimulation-induced ADs was often not observed when the $\mathbf{S 0 8 5 9}$ was applied. Right, For the traces shown in the middle panel, absolute values of the EEG traces were first integrated and the linear increase in the integral because of the baseline noise was subtracted. The first (gray) and the second (black) integrated ADs calculated from the left original traces are shown. The peak of the second integrated peak was larger than the first in control, but in S0859, the increase in the integrated peak was often not apparent. $\mathbf{D}$, Left, The peak of the integrated AD was measured, and the ratio of the peak to that from the first stimulation was calculated (mean \pm SEM). The integrated AD ratio increased for the second stimulus in control; however, the increase was not present when 50859 was applied ( $* p<0.05, n=6$ animals each, Student's $t$ test). Middle panels, Averaged AD occurrence rates (top) and durations (bottom). Note that ADs were always evoked by the first stimulation in all mice shown, as mice that did not exhibit an $A D$ with the fixed stimulation strength were omitted for further analysis. In the presence of $50859, A D$ occurrence dropped significantly during multiple days of stimulation. However, when AD did occur, the AD duration increased with each day of stimulation as in control $\left(n=5-6\right.$ animals each; $\chi^{2}=27.4,24.5,91$ for days $1,2,3$, respectively; $* * * * p<0.0001, \chi^{2}$ test). Note that $A D$ duration was calculated only when $A D$ occurred. By day 3 (D3), in the presence of 50859 , most stimulation failed to produce an $A D$ in all animals tested. Therefore, $A D$ duration was not calculated for $D 3$ for 50859 condition. Right, $A D$ durations (including $A D=0$ ) in response to each stimulation (total, 36 stimulations; 12 stim./d for $3 \mathrm{~d}$ ) were averaged across all animals in the control group and the 50859 group, respectively ( $n=5-6$ animals each; shown as lines). Daily averages were also calculated for each group and are shown as symbols ( $* * * p<0.001, * * * * p<0.0001$, daily averages of control vs 50859 group, Mann-Whitney $U$ test).

S0859-treated animals $\left(n=5-6\right.$ animals each; $\chi^{2}=27.4,24.5,91$ for days 1, 2, 3, respectively; $* * * * p<0.0001, \chi^{2}$ test; Fig. $5 D$, middle top). This was an interesting finding, which may suggest that the basal activity of NBC keeps the $\mathrm{pH}$ to somewhat alkaline state, which keeps a certain level of gap junctional uncoupling. The gap junction may become fully opened with continuous S0859 application, which makes $\left[\mathrm{K}^{+}\right]_{\mathrm{o}}$ clearance extremely 
efficient and $\mathrm{AD}$ can no longer be produced. Other unaccounted effects of NBC blockade may happen, which need to be addressed with future studies.

Continuous exposure to epileptiform activity for days resulted in prolongation of the AD duration in control conditions. Interestingly, when occurrence of AD did not fail, similar prolongation of the $\mathrm{AD}$ duration was observed in S0859-treated animals as well. This suggests that multiple mechanisms underlie the development of hyperexcitability and the prevention of alkalization could only prevent this process partially. However, the total $\mathrm{AD}$ durations, which includes situations where no $A D$ was produced $(A D=0 \mathrm{~s})$, were significantly shortened in the S0859 group ( $n=5-6$ animals each; $* * * p<0.001$, $* * * * p<0.0001$, daily averages of control vs $S 0859$ group, Mann-Whitney $U$ test; Fig. 5D, right). This suggest that in addition to the preventative action of S0859 in kindling development of epilepsy, it may also have a pure antiepileptic effect.

To evaluate whether S0859 administration has any adverse effect on the overall healthiness of the brain, we examined the EEG in the resting state in vivo. First, EEGs after 30 min exposure to control ACSF and to S0859 were compared. EEG traces (60 s) were converted to PSs and the AUC of these PSs was calculated for six frequency divisions (delta, $1-4 \mathrm{~Hz}$; theta, $4-7 \mathrm{~Hz}$; alpha, $8-13 \mathrm{~Hz}$; beta, $14-30 \mathrm{~Hz}$; gamma, $30-100 \mathrm{~Hz}$; high gamma, $80-150 \mathrm{~Hz}$ ). There were no significant difference between the two groups in any of the frequency divisions (AUCs; control day $1, n=6$; S0859 day $1, n=6 ; p=0.093$, $p=0.30, p=0.13, p=0.22, p=0.11, p=0.29$ for delta, theta, alpha, beta, gamma, high gamma, respectively; Student's $t$ test for theta, alpha, beta; Welch's $t$ test for delta, gamma, high gamma band power). The animals were then exposed to $6 \mathrm{~h}$ of ACSF or S0859 administrations daily while epileptiform activity was induced by electrical train stimuli 12 times every $30 \mathrm{~min}$. EEGs obtained on day 3, after 30 min of ACSF or S0859 administration and just before the first electrical train stimulation were also analyzed. There also was no significant difference between the two groups (AUCs; control day 3, $n=6$; S0859 day $3, n=5 ; p=0.39, p=0.15, p=0.17, p=0.18, p=0.15, p=0.32$ for delta, theta, alpha, beta, gamma, high gamma, respectively; Student's $t$ test for delta, theta, alpha, beta; Welch's $t$ test for gamma, high gamma-band power). This suggests that S0859 does not have a noticeable side effect on the normal neural activity.

In addition, we found that AUC of the delta band taken before the first electrical stimulus was significantly increased from day 1 to day 3 in control but not in S0859-administered animals (control day $1, n=6$; $\mathrm{AUC}=20.4 \pm 2.37 \mu \mathrm{V}^{2}$; control day $3, n=6$; AUC $=52.9 \pm 11.7 \mu \mathrm{V}^{2} ; * p<0.05$, Welch's $t$ test for control day 1 vs day3; S0859 day $1, n=6$; AUC $=50.7 \pm 14.6$ $\mu \mathrm{V}^{2}$; S0859 day $3, n=5 ; \quad \mathrm{AUC}=34.4 \pm 17.5 \mu \mathrm{V}^{2} ; p=0.49$, Student's $t$ test for $S 0859$ day 1 vs day 3). In focal epilepsy human patients, delta activity increases near the seizure onset zone (Lundstrom et al., 2019). Therefore, an increase in the delta activity in control animals on day 3 may reflect the pathologic state of the brain achieved through kindling. Such signs of epileptogenesis were absent in S0859-administered animals.

Together, using electrophysiology and ion concentration recording techniques, we show that astrocyte gap junction uncoupling is the key change associated with this modification in the brain status. Pharmacological intervention to stop the cascade of events leading to exacerbation of epilepsy was sought. This strategy of inhibiting the plasticity of astrocyte function rather than directly suppressing neuronal firing may provide a new therapeutic direction for a preventative medicine for epileptic patients.

\section{Discussion}

Epilepsy is known to become more severe with each seizure. Using the animal kindling model, it has been shown that the consecutive occurrence of seizures leads to a higher frequency and severity of seizures (Goddard, 1983; Lothman and Williamson, 1993). The amount of plastic changes that occur at the very early stage of epilepsy may be a prognosis of epileptogenesis. Describing the mechanisms of the initial response and the subsequent cascading events would be useful for devising a new preventative medicine for the suppression of epileptogenesis. Here, we demonstrated that acute plastic changes in the neuronal excitability occur in response to the first-time exposure to an epileptiform activity. We found that brief epileptiform activity was sufficient to activate the NBC in astrocytes, which resulted in the $\mathrm{HCO}_{3}{ }^{-}$influx and intracellular alkalization. Our work furthermore suggests that these alkaline $\mathrm{pH}$ shifts led to gap junction uncoupling and to the impairment of $\mathrm{K}^{+}$clearance. Under such circumstances, homeostatic mechanisms that normally allow local containment of hyperactivity become breached. Intervening with this plasticity process by blocking the NBC may become a promising strategy for prevention of epileptogenesis (Fig. 6).

Exacerbation of epilepsy occurs through multiple mechanisms, such as (1) an increase in excitatory synaptic transmission, (2) an increase in the number of excitatory synapses, (3) a loss of inhibitory interneurons, and (4) a hindrance of $\left[\mathrm{K}^{+}\right]_{\mathrm{o}}$ clearance. This hindrance of $\left[\mathrm{K}^{+}\right]_{\mathrm{o}}$ clearance could be because of a $\mathrm{K}^{+}$uptake problem and/or to the delay of intercellular $\mathrm{K}^{+}$diffusion caused by the disruption of the astrocyte network. When epileptiform activity spreads globally throughout the whole brain, reduction of $\left[\mathrm{K}^{+}\right]_{0}$ uptake by the Kir4.1 channel and/or the $\mathrm{Na}^{+} / \mathrm{K}^{+}$-ATPase become the major cause of the impairment of $\left[\mathrm{K}^{+}\right]_{\mathrm{K}}$ clearance. Intercellular $\mathrm{K}^{+}$diffusion likely contributes to the $\left[\mathrm{K}^{+}\right]_{\mathrm{o}}$ clearance at the very early stage of epileptogenesis when the hyperactivity is still relatively confined to a smaller area (Larsen et al., 2014; Breithausen et al., 2020). In this study, we focused on the acute plasticity of astrocyte gap junctions. Studies using transgenic mice lacking gap junction proteins or the application of gap junction inhibitors, such as carbenoxolone or gap27, a Cx43-specific inhibitor, have shown that the loss of gap junction communications between astrocytes led to a delay in the $\left[\mathrm{K}^{+}\right]_{\mathrm{o}}$ clearance both in vitro and in vivo (Wallraff et al., 2006; Bazzigaluppi et al., 2017). In addition, computational modeling showed a positive correlation between gap junction uncoupling and increased/prolonged $\left[\mathrm{K}^{+}\right]_{\mathrm{o}}$ transients (Du et al., 2018). In accordance with these studies, our results demonstrate the importance of astrocyte gap junctions in $\left[\mathrm{K}^{+}\right]_{\mathrm{o}}$ clearance at the first-time exposure to epileptiform activity and at the early stage of epileptogenesis.

Gap junction uncoupling in astrocytes has been suggested to occur at the advanced stage of epilepsy (Jin and Chen, 2011; Li et al., 2019; Breithausen et al., 2020). In human patients with epilepsy, loss of astrocytes occurs and astrocytes become uncoupled in the sclerotic hippocampus (Bedner et al., 2015). In immature mice, $5 \mathrm{~d}$ after hyperthermia-induced seizure, gap junction coupling became strongly inhibited (Khan et al., 2016). Inflammatory processes likely led to the changes in the Cx43 expression level and/or to the phosphorylation of the Cx43 C terminus (Khan et al., 2016). It should be noted, however, that enhanced gap junction was observed in some epilepsy 

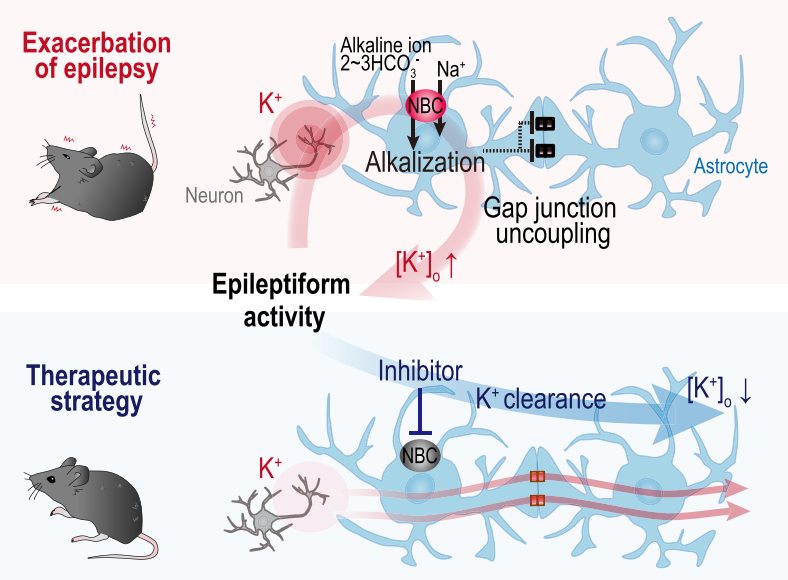

Figure 6. Mechanisms of the exacerbation of epilepsy and therapeutic strategy. Burst action potential firing of neurons leads to excess amount of $\mathrm{K}^{+}$efflux from the cytosols of neurons to the extracellular space. The $\mathrm{K}^{+}$leads to depolarization of astrocytes, NBC is activated, and, with the influx of $\mathrm{HCO}_{3}{ }^{-}$, intracellular $\mathrm{pH}$ of astrocytes becomes alkalized. Gap junction uncoupling occurs as a consequence and $\mathrm{K}^{+}$clearance becomes impaired, and the brain becomes more susceptible to hyperactivity (exacerbation of epilepsy). The alkaline shifts of the astrocytes in response to epileptiform activity can be inhibited with NBC blocker. Gap junction uncoupling can then be avoided, which would allow smooth clearance of the $\mathrm{K}^{+}$ through the intercellular network of astrocytes. Suppressing the detrimental plasticity of the astrocyte function in response to initial occurrences of seizures may prevent the development of epileptogenesis and could become a new therapeutic strategy.

studies, and the contradiction may be coming from the use of different experimental paradigms (De Pina-Benabou et al., 2001; Rouach et al., 2008). It is thus important to determine how the plastic changes in gap junction are initiated. In contrast to the articles introduced above, which studied changes occurring on a timescale of days to years, we focused on the very acute phase of epilepsy. We found that plastic changes of gap junctional coupling occur after only a few minutes of epileptiform activity. This conclusion is supported by the recent report by Wang et al. (2020) showing that short-term epileptiform activity indeed weakened the gap junction coupling and spatial $\mathrm{K}^{+}$distribution.

Electrophysiological studies have shown that gap junction uncoupling was induced by intracellular alkalization in ventricular myocytes (Swietach et al., 2007) and in vascular endothelial cells (Boedtkjer et al., 2013). However, it should be noted that it has also been reported that acidification could also lead to uncoupling (Swietach et al., 2007). In either case, the intracellular $\mathrm{pH}$ change appears to be linked to gap junction uncoupling. It is possible that (1) activation of mitogen-activated protein kinase pathway could lead to gap junction closure. Following (1), (2) internalization of $\mathrm{Cx} 43$ could occur via the Src pathway, which leads to the decrease in the number of gap junction proteins on the plasma membrane. Another possibility is that (3) interaction of $\mathrm{Cx} 43$ and the cytoskeletal elements may lead to a smaller gap junction conductance (Solan and Lampe, 2009, 2014; MárquezRosado et al., 2012; Thévenin et al., 2013). It seems unlikely that protein expression levels change during the short time course that we mainly focused on. Therefore, intracellular $\mathrm{pH}$ shifts caused by NBC activation presumably leads to gap junction closure by (1) the direct effect of the intracellular $\mathrm{pH}$ on the connexin open probability, (2) the phosphorylation of connexins, and/or (3) the protein binding to connexins, leading to their functional alterations.
Alkaline $\mathrm{pH}$ shifts occur in astrocytes in response to seizurelike activity (Chesler and Kraig, 1987; Raimondo et al., 2016). Upon epileptiform activity, $\mathrm{K}^{+}$is discharged to the extracellular space from the inside of neurons. Increase in the $\left[\mathrm{K}^{+}\right]_{\mathrm{o}}$ leads to the depolarization of the astrocytes because much of the $\mathrm{K}^{+}$ channels in astrocytes is constitutively in a highly open probability state, and the membrane potential of astrocytes basically follows the changes in the $\left[\mathrm{K}^{+}\right]_{\mathrm{o}}$ (Stephan et al., 2012; Karus et al., 2015). Cell depolarization activates the NBC in astrocytes, and, as a result, $\mathrm{HCO}_{3}{ }^{-}$influx occurs, which leads to intracellular alkalization (Chesler and Kraig, 1989; Deitmer and Szatkowski, 1990; Hampson et al., 1994; Pappas and Ransom, 1994; Scemes and Spray, 2012; Raimondo et al., 2016). In accordance with this scheme, application of the NBC blocker S0859 led to the prevention of intracellular alkalization of astrocytes. Although NBC is also expressed in neurons, previous reports suggest that pharmacological NBC inhibition by S0859, effectively targeted intracellular $\mathrm{pH}$ shifts of astrocytes, rather than that of neurons (Raimondo et al., 2016). It has also been shown that electrogenic NBC is highly expressed in astrocytes compared with neurons, and also, RNA transcripts for NBC encoding gene are higher in astrocytes (Giffard et al., 2000; Zhang et al., 2014). NBCn1, an electroneutral type of NBC, has been shown to be expressed mostly in excitatory postsynaptic membrane (Park et al., 2010). Knocking out this gene resulted in reduced susceptibility to seizure induction by NMDA application (Park et al., 2019). This was because of the downregulation of NMDARs on neuronal membrane. Chronic blockade of neuronal NBC may also have the beneficial effect of reducing epileptic seizures through pathways other than the inhibition of astrocyte gap junction uncoupling.

It has also been shown that NBCel activation in astrocytes induces the influx of one $\mathrm{Na}^{+}$along with two $\mathrm{HCO}_{3}{ }^{-}$; thus, the net charge is negative (Astion et al., 1987; Alberts et al., 1994; Theparambil et al., 2015). Therefore, the activation of NBC in astrocytes results in their repolarization or hyperpolarization. If NBC operating in the inward direction is constitutively active, blockade of NBC by S0859 would lead to a more depolarized potential compared with control. Therefore, in the presence of S0859, one would imagine that $\mathrm{K}^{+}$efflux from the depolarized astrocytes may occur. However, our results show that S0859 rather had an antiepileptic effect. Thus, even if basal depolarization is induced in astrocytes by the application of S0859, the antiepileptic effect overwhelmed the proepileptic effect from depolarization. It has also been shown that the conductance of gap junctions became increased when astrocytes were hyperpolarized (Revilla et al., 2000). Blocking the NBC by S0859 could lead to gap junction uncoupling by depolarization. However, our results show that the blockade of NBC led to the prevention of gap junction uncoupling. Therefore, the key mechanism underlying gap junction uncoupling is likely to be the alkalization induced by NBC activation. The membrane potential alterations induced by NBC activation play rather a minor role in modifying the gap junction coupling.

In addition to these findings, using a rapid kindling in vivo animal model, we showed that continuous pharmacological inhibition of NBC resulted in the downregulation of both AD durations and $\mathrm{AD}$ occurrence. This result suggests that, because of the basal inward NBC activity, the cytosol of the astrocytes remains somewhat alkaline, which keeps a certain level of gap junction uncoupling. With continuous blockade of NBC, the gap junctions may become fully open, resulting in an above-baseline 
efficiency of $\mathrm{K}^{+}$clearance promoting an antiepileptic effect. However, other effects of S0859 administration also need to be taken into consideration. NBC has also been suggested to be related to glycogenesis. Therefore, continuous NBC blockade may affect the energy metabolism in astrocytes, which in turn would ultimately affect neuronal activity (Rouach et al., 2000; Fernández-Moncada et al., 2018).

\section{References}

Aida T, Chiyo K, Usami T, Ishikubo H, Imahashi R, Wada Y, Tanaka KF, Sakuma T, Yamamoto T, Tanaka K (2015) Cloning-free CRISPR/Cas system facilitates functional cassette knock-in in mice. Genome Biol 16:87.

Alberts B, Bray D, Lewis J, Raff M, Roberts K, Watson JD (1994) Membrane transport of small molecules and the ionic basis of membrane excitability. In: Molecular biology of the cell, Ed 3, pp 507-549. New York: Garland Science.

Astion ML, Coles JA, Orkand RK (1987) Effects of bicarbonate on glial cell membrane potential in Necturus optic nerve. Neurosci Lett 76:47-52.

Bazzigaluppi P, Weisspapir I, Stefanovic B, Leybaert L, Carlen PL (2017) Astrocytic gap junction blockade markedly increases extracellular potassium without causing seizures in the mouse neocortex. Neurobiol Dis 101:1-7.

Bedner P, Dupper A, Hüttmann K, Müller J, Herde MK, Dublin P, Deshpande T, Schramm J, Häussler U, Haas CA, Henneberger C, Theis M, Steinhäuser C (2015) Astrocyte uncoupling as a cause of human temporal lobe epilepsy. Brain 138:1208-1222.

Bélanger M, Magistretti PJ (2009) The role of astroglia in neuroprotection. Dialogues Clin Neurosci 11:281-296.

Bellot-Saez A, Kékesi O, Morley JW, Buskila Y (2017) Astrocytic modulation of neuronal excitability through $\mathrm{K}^{+}$spatial buffering. Neurosci Biobehav Rev 77:87-97.

Beppu K, Sasaki T, Tanaka KF, Yamanaka A, Fukazawa Y, Shigemoto R, Matsui K (2014) Optogenetic countering of glial acidosis suppresses glial glutamate release and ischemic brain damage. Neuron 81:314-320.

Bizzarri R, Arcangeli C, Arosio D, Ricci F, Faraci P, Cardarelli F, Beltram F (2006) Development of a novel GFP-based ratiometric excitation and emission pH indicator for intracellular studies. Biophys J 90:3300-3314.

Boedtkjer E, Kim S, Aalkjaer C (2013) Endothelial alkalinisation inhibits gap junction communication and endothelium-derived hyperpolarisations in mouse mesenteric arteries. J Physiol 591:1447-1461.

Breithausen B, Kautzmann S, Boehlen A, Steinhäuser C, Henneberger C (2020) Limited contribution of astroglial gap junction coupling to buffering of extracellular $\mathrm{K}^{+}$in CA1 stratum radiatum. Glia 68:918-931.

Chen B, Choi H, Hirsch LJ, Katz A, Legge A, Buchsbaum R, Detyniecki K (2017) Psychiatric and behavioral side effects of antiepileptic drugs in adults with epilepsy. Epilepsy Behav 76:24-31.

Chesler M, Kraig RP (1987) Intracellular pH of astrocytes increases rapidly with cortical stimulation. Am J Physiol Regul Integr Comp Physiol 253: R666-R670.

Chesler M, Kraig RP (1989) Intracellular pH transients of mammalian astrocytes. J Neurosci 9:2011-2019.

Close B, Banister K, Baumans V, Bernoth EM, Bromage N, Bunyan J, Erhardt W, Flecknell P, Gregory N, Hackbarth H, Morton D, Warwick C (1997) Recommendations for euthanasia of experimental animals: part 2. DGXT of the European Commission. Lab Anim 31:1-32.

de Curtis M, Uva L, Gnatkovsky V, Librizzi L (2018) Potassium dynamics and seizures: why is potassium ictogenic? Epilepsy Res 143:50-59.

De Pina-Benabou MH, Srinivas M, Spray DC, Scemes E (2001) Calmodulin kinase pathway mediates the $\mathrm{K}^{+}$-induced increase in gap junctional communication between mouse spinal cord astrocytes. J Neurosci 21:66356643.

Deitmer JW, Szatkowski M (1990) Membrane potential dependence of intracellular $\mathrm{pH}$ regulation by identified glial cells in the leech central nervous system. J Physiol 421:617-631.

Deshpande T, Li T, Henning L, Wu Z, Müller J, Seifert G, Steinhäuser C, Bedner P (2020) Constitutive deletion of astrocytic connexins aggravates kainate-induced epilepsy. Glia 68:2136-2147.

Du M, Li J, Chen L, Yu Y, Wu Y (2018) Astrocytic Kir4.1 channels and gap junctions account for spontaneous epileptic seizure. PLoS Comput Biol 14:e1005877.
Escartin C, Rouach N (2013) Astroglial networking contributes to neurometabolic coupling. Front Neuroenergetics 5:4.

Etemadi F, Sayyah M, Pourbadie HG, Babapour V (2015) Assessment of the optimal stimulus pattern to achieve rapid dorsal hippocampal kindling in rats. Basic Clin Neurosci 6:39-44.

Eto W, Hirano K, Hirano M, Nishimura J, Kanaide H (2003) Intracellular alkalinization induces $\mathrm{Ca}^{2+}$ influx via non-voltage-operated $\mathrm{Ca}^{2+}$ channels in rat aortic smooth muscle cells. Cell Calcium 34:477-484.

Fernández-Moncada I, Ruminot I, Robles-Maldonado D, Alegría K, Deitmer JW, Barros LF (2018) Neuronal control of astrocytic respiration through a variant of the Crabtree effect. Proc Natl Acad Sci U S A 115:1623-1628.

Gerkau NJ, Kafitz KW, Rose CR (2019) Imaging of local and global sodium signals in astrocytes. In: Astrocytes: methods and protocols, methods in molecular biology, Vol 1938 (Benedetto BD, ed), pp 187-202. Heidelberg: Springer Nature.

Giaume C, Koulakoff A, Roux L, Holcman D, Rouach N (2010) Astroglial networks: a step further in neuroglial and gliovascular interactions. Nat Rev Neurosci 11:87-99.

Giffard RG, Papadopoulos MC, Van Hooft JA, Xu L, Giuffrida R, Monyer H (2000) The electrogenic sodium bicarbonate cotransporter: developmental expression in rat brain and possible role in acid vulnerability. J Neurosci 20:1001-1008.

Goddard GV (1983) The kindling model of epilepsy. Trends Neurosci 6:275279.

Goddard GV, McIntyre DC, Leech CK (1969) A permanent change in brain function resulting from daily electrical stimulation. Exp Neurol 25:295330.

González-Nieto D, Gómez-Hernández JM, Larrosa B, Gutiérrez C, Muñoz MD, Fasciani I, O’Brien J, Zappalà A, Cicirata F, Barrio LC (2008) Regulation of neuronal connexin-36 channels by pH. Proc Natl Acad Sci U S A 105:17169-17174.

Grichtchenko II, Chesler M (1994) Depolarization-induced alkalinization of astrocytes in gliotic hippocampal slices. Neuroscience 62:1071-1078.

Griemsmann S, Höft SP, Bedner P, Zhang J, Von Staden E, Beinhauer A, Degen J, Dublin P, Cope DW, Richter N, Crunelli V, Jabs R, Willecke K, Theis M, Seifert G, Kettenmann H, Steinhäuser C (2015) Characterization of panglial gap junction networks in the thalamus, neocortex, and hippocampus reveals a unique population of glial cells. Cereb Cortex 25:3420-3433.

Haack N, Durry S, Kafitz KW, Chesler M, Rose CR (2015) Double-barreled and concentric microelectrodes for measurement of extracellular ion signals in brain tissue. J Vis Exp 2015:e53058.

Hagos L, Hülsmann S (2016) Unspecific labelling of oligodendrocytes by sulforhodamine 101 depends on astrocytic uptake via the thyroid hormone transporter OATP1C1 (SLCO1C1). Neurosci Lett 631:13-18.

Hampson ECGM, Weiler R, Vaney DI (1994) pH-gated dopaminergic modulation of horizontal cell gap junctions in mammalian retina. Proc Biol Sci 255:67-72.

Hertz L, Gerkau NJ, Xu J, Durry S, Song D, Rose CR, Peng L (2015) Roles of astrocytic $\mathrm{Na}^{+}, \mathrm{K}^{+}$-ATPase and glycogenolysis for $\mathrm{K}^{+}$homeostasis in mammalian brain. J Neurosci Res 93:1019-1030.

Hirase H, Qian L, Barthó P, Buzsáki G (2004) Calcium dynamics of cortical astrocytic networks in vivo. PLoS Biol 2:e96.

Hülsmann S, Hagos L, Heuer H, Schnell C (2017) Limitations of sulforhodamine 101 for brain imaging. Front Cell Neurosci 11:44.

Jin MM, Chen Z (2011) Role of gap junctions in epilepsy. Neurosci Bull 27:389-406.

Kafitz KW, Meier SD, Stephan J, Rose CR (2008) Developmental profile and properties of sulforhodamine 101-labeled glial cells in acute brain slices of rat hippocampus. J Neurosci Methods 169:84-92.

Kalilani L, Sun X, Pelgrims B, Noack-Rink M, Villanueva V (2018) The epidemiology of drug-resistant epilepsy: a systematic review and meta-analysis. Epilepsia 59:2179-2193.

Karus C, Mondragão MA, Ziemens D, Rose CR (2015) Astrocytes restrict discharge duration and neuronal sodium loads during recurrent network activity. Glia 63:936-957.

Kelly T, Kafitz KW, Roderigo C, Rose CR (2009) Ammonium-evoked alterations in intracellular sodium and $\mathrm{pH}$ reduce glial glutamate transport activity. Glia 57:921-934.

Khan D, Dupper A, Deshpande T, Graan PNED, Steinhäuser C, Bedner P (2016) Experimental febrile seizures impair interastrocytic gap junction coupling in juvenile mice. J Neurosci Res 94:804-813. 
Langer J, Stephan J, Theis M, Rose CR (2012) Gap junctions mediate intercellular spread of sodium between hippocampal astrocytes in situ. Glia 60:239-252.

Larsen BR, Assentoft M, Cotrina ML, Hua SZ, Nedergaard M, Kaila K, Voipio J, Macaulay N (2014) Contributions of the $\mathrm{Na}^{+} / \mathrm{K}^{+}$-ATPase, NKCC1, and Kir4.1 to hippocampal $\mathrm{K}^{+}$clearance and volume responses. Glia 62:608-622.

Li Q, Li QQ, Jia JN, Liu ZQ, Zhou HH, Mao XY (2019) Targeting gap junction in epilepsy: perspectives and challenges. Biomed Pharmacother 109:57-65.

Lothman EW, Williamson JM (1993) Rapid kindling with recurrent hippocampal seizures. Epilepsy Res 14:209-220.

Lundstrom BN, Boly M, Duckrow R, Zaveri HP, Blumenfeld H (2019) Slowing less than $1 \mathrm{~Hz}$ is decreased near the seizure onset zone. Sci Rep 9:6218.

Márquez-Rosado L, Solan JL, Dunn CA, Norris RP, Lampe PD (2012) Connexin 43 phosphorylation in brain, cardiac, endothelial and epithelial tissues. Biochim Biophys Acta 1818:1985-1992.

Minta A, Tsien RY (1989) Fluorescent indicators for cytosolic sodium. J Biol Chem 264:19449-19457.

Nicholson BJ, Weber PA, Cao F, Chang HC, Lampe P, Goldberg G (2000) The molecular basis of selective permeability of connexins is complex and includes both size and charge. Braz J Med Biol Res 33:369-378.

Nimmerjahn A, Kirchhoff F, Kerr JND, Helmchen F (2004) Sulforhodamine 101 as a specific marker of astroglia in the neocortex in vivo. Nat Methods 1:31-37.

Pannasch U, Derangeon M, Chever O, Rouach N (2012) Astroglial gap junctions shape neuronal network activity. Commun Integr Biol 5:248-254.

Pappas CA, Ransom BR (1994) Depolarization-induced alkalinization (DIA) in rat hippocampal astrocytes. J Neurophysiol 72:2816-2826.

Park HJ, Rajbhandari I, Yang HS, Lee S, Cucoranu D, Cooper DS, Klein JD, Sands JM, Choi I (2010) Neuronal expression of sodium/bicarbonate cotransporter NBCn1 (SLC4A7) and its response to chronic metabolic acidosis. Am J Physiol Cell Physiol 298:1018-1028.

Park HJ, Gonzalez-Islas CE, Kang Y, Li JM, Choi I (2019) Deletion of the Na/ $\mathrm{HCO}_{3}$ transporter NBCn1 protects hippocampal neurons from NMDAinduced seizures and neurotoxicity in mice. Sci Rep 9:15981.

Paxinos J, Franklin KBJ (2001) The mouse brain in stereotaxic coordinates, Ed 2. San Diego: Academic.

Pernelle G, Nicola W, Clopath C (2018) Gap junction plasticity as a mechanism to regulate network-wide oscillations. PLoS Comput Biol 14: e1006025.

Raimondo JV, Tomes H, Irkle A, Kay L, Kellaway L, Markram H, Millar RP, Akerman CJ (2016) Tight coupling of astrocyte $\mathrm{pH}$ dynamics to epileptiform activity revealed by genetically encoded $\mathrm{pH}$ sensors. J Neurosci 36:7002-7013.

Revilla A, Bennett MVL, Barrio LC (2000) Molecular determinants of membrane potential dependence in vertebrate gap junction channels. Proc Natl Acad Sci U S A 97:14760-14765.

Rose CR, Ransom BR (1996) Intracellular sodium homeostasis in rat hippocampal astrocytes. J Physiol 491:291-305.

Rouach N, Glowinski J, Giaume C (2000) Activity-dependent neuronal control of gap-junctional communication in astrocytes. J Cell Biol 149:15131526.

Rouach N, Koulakoff A, Abudara V, Willecke K, Giaume C (2008) Astroglial metabolic networks sustain hippocampal synaptic transmission. Science 322:1551-1555.

Sasaki T, Beppu K, Tanaka KF, Fukazawa Y, Shigemoto R, Matsui K (2012) Application of an optogenetic byway for perturbing neuronal activity via glial photostimulation. Proc Natl Acad Sci U S A 109:20720-20725.

Scemes E, Spray DC (2012) Extracellular $\mathrm{K}^{+}$and astrocyte signaling via connexin and pannexin channels. Neurochem Res 37:2310-2316.
Schnell C, Hagos Y, Hülsmann S (2012) Active sulforhodamine 101 uptake into hippocampal astrocytes. PLoS One 7:e49398.

Shigetomi E, Kracun S, Sofroniew MV, Khakh BS (2010) A genetically targeted optical sensor to monitor calcium signals in astrocyte processes. Nat Neurosci 13:759-766

Solan JL, Lampe PD (2009) Connexin43 phosphorylation: structural changes and biological effects. Biochem J 419:261-272.

Solan JL, Lampe PD (2014) Specific Cx43 phosphorylation events regulate gap junction turnover in vivo. FEBS Lett 588:1423-1429.

Steinhäuser C, Seifert G, Bedner P (2012) Astrocyte dysfunction in temporal lobe epilepsy: $\mathrm{k}^{+}$channels and gap junction coupling. Glia 60:11921202.

Stephan J, Haack N, Kafitz KW, Durry S, Koch D, Hochstrate P, Seifert G, Steinhäuser C, Rose CR (2012) Kir4.1 channels mediate a depolarization of hippocampal astrocytes under hyperammonemic conditions in situ. Glia 60:965-978.

Stosiek C, Garaschuk O, Holthoff K, Konnerth A (2003) In vivo two-photon calcium imaging of neuronal networks. Proc Natl Acad Sci U S A 100:7319-7324.

Swietach P, Rossini A, Spitzer KW, Vaughan-Jones RD (2007) $\mathrm{H}^{+}$ion activation and inactivation of the ventricular gap junction: a basis for spatial regulation of intracellular $\mathrm{pH}$. Circ Res 100:1045-1054.

Tanaka KF, Matsui K, Sasaki T, Sano H, Sugio S, Fan K, Hen R, Nakai J, Yanagawa Y, Hasuwa H, Okabe M, Deisseroth K, Ikenaka K, Yamanaka A (2012) Expanding the repertoire of optogenetically targeted cells with an enhanced gene expression system. Cell Rep 2:397-406.

Theparambil SM, Naoshin Z, Thyssen A, Deitmer JW (2015) Reversed electrogenic sodium bicarbonate cotransporter 1 is the major acid loader during recovery from cytosolic alkalosis in mouse cortical astrocytes. J Physiol 593:3533-3547.

Thévenin AF, Kowal TJ, Fong JT, Kells RM, Fisher CG, Falk MM (2013) Proteins and mechanisms regulating gap-junction assembly, internalization, and degradation. Physiology (Bethesda) 28:93-116.

Urschel S, Höher T, Schubert T, Alev C, Söhl G, Wörsdörfer P, Asahara T, Dermietzel R, Weiler R, Willecke K (2006) Protein kinase A-mediated phosphorylation of connexin 36 in mouse retina results in decreased gap junctional communication between AII amacrine cells. J Biol Chem 281:33163-33171

Verkhratsky A, Kettenmann H (1996) Calcium signalling in glial cells. Trends Neurosci 19:346-352.

Verkhratsky A, Kirchhoff F (2007) Glutamate-mediated neuronal-glial transmission. J Anat 210:651-660.

Verkhratsky A, Nedergaard M (2018) Physiology of astroglia. Physiol Rev 98:239-389.

Wallraff A, Köhling R, Heinemann U, Theis M, Willecke K, Steinhäuser C (2006) The impact of astrocytic gap junctional coupling on potassium buffering in the hippocampus. J Neurosci 26:5438-5447.

Wang HZ, Veenstra RD (1997) Monovalent ion selectivity sequences of the rat connexin43 gap junction channel. J Gen Physiol 109:491-507.

Wang Q, Wang W, Aten S, Kiyoshi CM, Du Y, Zhou M (2020) Epileptiform neuronal discharges impair astrocyte syncytial isopotentiality in acute hippocampal slices. Brain Sci 10:208.

Whittington MA, Stanford IM, Colling SB, Jefferys JGR, Traub DR (1997) Spatiotemporal patterns of $\gamma$ frequency oscillations tetanically induced in the rat hippocampal slice. J Physiol 502:591-607.

Zhang Y, Chen K, Sloan SA, Bennett ML, Scholze AR, O'Keeffe S, Phatnani HP, Guarnieri P, Caneda C, Ruderisch N, Deng S, Liddelow SA, Zhang C, Daneman R, Maniatis T, Barres BA, Wu JQ (2014) An RNA-sequencing transcriptome and splicing database of glia, neurons, and vascular cells of the cerebral cortex. J Neurosci 34:11929-11947. 